NBER WORKING PAPER SERIES

ANNUITIZED WEALTH AND POST-RETIREMENT SAVING

John Laitner

Daniel Silverman

Dmitriy Stolyarov

Working Paper 20547

http://www.nber.org/papers/w20547

\author{
NATIONAL BUREAU OF ECONOMIC RESEARCH \\ 1050 Massachusetts Avenue \\ Cambridge, MA 02138 \\ October 2014
}

We thank seminar audiences at Brigham Young University, Kansai University, the MRRC Researcher Workshop, the NBER Summer Institute, and the University of Michigan for their many helpful comments. This work was supported by NIH/NIA grant R01-AG030841-01. The opinions and conclusions are solely those of the authors and should not be considered as representing the opinions or policy of any agency of the Federal Government, nor the views of the National Bureau of Economic Research.

NBER working papers are circulated for discussion and comment purposes. They have not been peerreviewed or been subject to the review by the NBER Board of Directors that accompanies official NBER publications.

(C) 2014 by John Laitner, Daniel Silverman, and Dmitriy Stolyarov. All rights reserved. Short sections of text, not to exceed two paragraphs, may be quoted without explicit permission provided that full credit, including $\odot$ notice, is given to the source. 
Annuitized Wealth and Post-Retirement Saving

John Laitner, Daniel Silverman, and Dmitriy Stolyarov

NBER Working Paper No. 20547

October 2014

JEL No. D91,E21,H55

\section{ABSTRACT}

We introduce a tractable model of post-retirement saving behavior in which households have a precautionary motive arising from uninsured health status risks. The model distinguishes between annuitized and non-annuitized wealth, emphasizes the importance of asset composition in determining optimal household behavior, and includes an extension allowing late-in-life exchange transactions among relatives. We consider three puzzles in micro data - rising cohort average wealth of retirees, lack of demand for market annuities, and the relative scarcity of bequests - and show that our model can provide intuitive explanations for each.

John Laitner

Department of Economics

University of Michigan

611 Tappan Street

311 Lorch Hall

Ann Arbor, MI 48109-1220

and NBER

jlaitner@umich.edu

Daniel Silverman

Department of Economics

W.P. Carey School of Business

Arizona State University

P.O. Box 879801

Tempe, AZ 85287-9801

and NBER

dsilver3@asu.edu
Dmitriy Stolyarov

University of Michigan

Department of Economics

611 Tappan Ave, Room 238

Ann Arbor, MI 48109-1220

stolyar@umich.edu 


\title{
Annuitized Wealth and Post-Retirement Saving
}

\author{
John Laitner \\ University of Michigan \\ Daniel Silverman \\ Arizona State University \\ Dmitriy Stolyarov \\ University of Michigan
}

September 18, 2014

\begin{abstract}
We introduce a tractable model of post-retirement saving behavior in which households have a precautionary motive arising from uninsured health status risks. The model distinguishes between annuitized and non-annuitized wealth, emphasizes the importance of asset composition in determining optimal household behavior, and includes an extension allowing late-in-life exchange transactions among relatives. We consider three puzzles in micro data - rising cohort average wealth of retirees, lack of demand for market annuities, and the relative scarcity of bequests - and show that our model can provide intuitive explanations for each.
\end{abstract}

\section{Introduction}

Recent empirical analyses of consumption and saving have fueled interest in modeling the behavior of households after retirement. ${ }^{1}$ This paper develops an analytically tractable, lifecycle model of post-retirement behavior that incorporates health and mortality uncertainty and captures real-world restrictions on the set of available financial securities and insurance instruments. The model pays special attention to household portfolios, specifically to the distinct properties and roles of annuities versus liquid assets. We use the model to examine three puzzles in micro data: (i) the steady or rising average wealth of retired cohorts; ${ }^{2}$ (ii) the lack of demand for market annuities; ${ }^{3}$ and, (iii) the relative scarcity of accidental bequests. ${ }^{4}$ While each puzzle appears to challenge conventional economic theory, this paper offers a modeling formulation that is consistent with all three facts, and that provides intuitive explanations for each. The model highlights the imporatnce of portfolio options and choices for post-retirement behavior.

In our framework, each household begins retirement in a healthy state, though health tends to decline; a low health state brings an increased mortality rate and may raise the

\footnotetext{
${ }^{1}$ See, e.g., Hubbard et al. [1994,1995], Palumbo [1999], Sinclair and Smetters [2004], Dynan et al. [2004], Scholz et al. [2006], Ameriks et al. [2010], DeNardi et al. [2011], Love et al. [2009], Finkelstein et al. [2011], and Poterba et al. [2011, 2012].

${ }^{2}$ E.g., Poterba et al. [2012], De Nardi et al. [2010], and many others. See also Section 6.

${ }^{3}$ E.g., Friedman and Warshawsky [1990], Mitchell et al. [1999]), and many others.

${ }^{4}$ E.g., Laitner and Ohlsson [2001] and Laitner and Sonnega [2010, 2012] and others.
} 
marginal utility of expenditure. The timing of the transition to a low health state, and its duration, are uncertain. We follow the literature in assuming that health state is not insurable. Here it is important to distinguish between medical conditions, which are often insured, and a "health state" associated with needs for long-term care that are often uninsured. Virtually all elderly Americans have insurance for their medical conditions. However, troubles with "activities of daily living" (ADLs), which for us define low "health state," are difficult, in practice, for third parties to verify. ${ }^{5}$ Asymmetric information on health state then restricts the availability of private long-term care insurance and may well make precautionary saving a second-best choice.

Our analysis proceeds in three steps. First, we consider a baseline version of the model in which a household obtains an endowment of "primary annuities" - from Social Security and defined benefit pensions — at retirement. These annuities have low transactions costs and may be compulsory. With this baseline version of the model, we consider the possibility of continued accumulation of liquid wealth after retirement.

A first key finding is that wealth accumulation after retirement is possible, but not a simple consequence of health expenditure uncertainty. In our framework, households in poor health always spend down their liquid wealth. Because high mortality limits the number of survivors in poor health, it is the behavior of those in the high health state that is pivotal in determining the time path of cohort average bequeathable net worth. Our analysis indicates that either accumulation or decumulation can be optimal for healthy households, and that those with substantial annuitization may be the most likely to continue saving after retirement.

This first finding complements existing theories of post-retirement saving that emphasize the importance of health expenditure risk (e.g., De Nardi et al. [2010], Laibson [2011], and Amerkis et al. [2014]), and shows the central role of portfolio composition in determining wealth paths after retirement. On average, good health status lasts much longer than poor health. If the real interest rate, $r$, is high enough, liquid assets are very attractive. A household can live on its interest income while good health status lasts, and then begin to spend its principal when poor health arrives. Accumulation of liquid assets after retirement while in good health is the rule. If, however, $r$ is lower, a household will desire a mixture of annuities and liquid wealth. In our calibrations, this is the interesting case. With a moderate or low $r$, a desired stationary ratio of liquid assets to annuities emerges. A household starting below the ratio wants to save after retirement to accumulate more liquid wealth; a household starting above the ratio immediately begins to dissave. We relate the desired ratio to parameter values and then compare it with micro evidence on portfolio composition. Calibrations show that rising average cohort liquid wealth after retirement can easily emerge.

In a second step, Section 7 extends the baseline model to allow retiring households to adjust their initial portfolio through the purchase of secondary annuities. We take secondary annuities to be individual, market-based annuities. Again, they can condition only on mortality. Due to adverse selection and other transactions costs, they may carry a substantial "load." Davidoff et al. [2005], Diamond [2004], Sinclair and Smetters [2004], Reichling and Smetters [2013], and others examine the demand for annuities given environments where their inflexibility is constraining.

In all calibrated examples of this extended model, we find that if annuity pricing were actuarially fair, households would choose full annuitization. In practice, however, annuities pay

\footnotetext{
${ }^{5}$ Activities of daily living that are critical to the elderly living alone include bathing, eating, dressing, walking across a room, and getting out of bed.
} 
a lower than actuarially fair rate of return (cf. Friedman and Warshawsky [1990], Mitchell et al. [1999]). When households in the model start with the initial endowment of primary annuities typical of retirement-age households in the data and face annuity returns in the lower segment of the empirically observed range, they optimally choose not to purchase additional (secondary) annuities. Their subsequent wealth accumulation behavior then remains the same as in the basic model. In this way, our framework is consistent with both rising cohort average wealth and zero demand for secondary annuities. This result obtains even though our households lack a bequest motive. ${ }^{6}$

In a third step, we analyze a still more general version of the model that includes an additional annuity-like instrument: if family members have reliable information about each other's health state, they can offer non-market annuities to relatives in poor health (Kotlikoff and Spivak [1981]). For example, family members may commit to providing lifetime assistance with ADLs for an elderly relative in poor health in exchange for a lump sum payment. While opportunities for intergenerational exchange may be changing over time, evidence from co-residence patterns (CBO [1988]) and family-line time inputs for informal care (AARP [2011]) indicate that assistance from relatives remains extremely significant in the US. ${ }^{7}$

Analysis of the potential implications of these non-market exchanges provides a second set of key findings. Specifically, the option to purchase a non-market annuity upon reaching poor health can completely eliminate demand for secondary annuities. In fact, households may even want to reduce their primary annuities — as by claiming Social Security benefits relatively early.

In addition to offering a new explanation for the second micro data puzzle, non-market annuities can, we show, reconcile the thin market for secondary annuities with the relative scarcity of accidental bequests. If demand for market annuities is low and penalties for running out of liquid assets in poor health are high, we might expect to see almost $100 \%$ of households leaving (accidental) bequests (see Section 8). Yet only 20-40 percent of households report an inheritance. Non-market annuities can provide the reason, as follows: a household that contracts with relatives for care obtains an implicit annuity; therefore, annuitization can, by the last stage of life, be far more widespread than purchases of market annuity instruments suggest.

This paper provides a formulation sufficiently detailed to allow meaningful calibrations but sufficiently simple to yield intuitive, analytic insights into household behavior. Our analysis reveals the versatility of the framework. Even as, in each step, the model becomes increasingly general, the qualitative features of optimal behavior continue to be described by two simple phase diagrams. This versatility is valuable because, by adding generality incrementally, we see the central roles that actuarially unfair pricing and non-market annuities can play in determining the level and composition of wealth after retirement. Adding still more features to our model, such as a bequest motive or public assistance, will not undermine the central role of portfolio composition for wealth accumulation behavior; rather, it will introduce subtle interactions between the various types of saving motives. ${ }^{8}$

The organization of this paper is as follows. Section 2 presents our baseline model and

\footnotetext{
${ }^{6}$ Amerkis et al. [2014] examine the annuity puzzle in more detail and present a framework that is aimed at quantifying the contributions of bequest motive, precautionary motive and actuarially unfair pricing to retiree demand for annuities. Their focus is on using survey data to identify agents' preference parameters.

${ }^{7}$ See also references in Section 8.

${ }^{8}$ Indeed, we study these interactions in detail in a separate paper, Laitner et al. [2013].
} 
assumptions. Sections 3-4 analyze the optimal consumption problem in high and low health states. Section 5 calibrates the model's parameters. Section 6 analyzes cohort average bequeathable wealth trajectories after retirement. Sections 7-8 examine optimal annuitization at retirement and family-line assistance for those in poor health. Section 9 concludes.

\section{$2 \quad$ Model}

We study single-person households in their retirement years. At any age $s$, a household's health state, $h$, is either "high," $H$, or "low," $L$. The household starts retirement with $h=H$. There is a Poisson process with hazard rate $\lambda>0$ such that at the first Poisson event the household transitions to the low health state. Once in state $h=L$, the household begins a second Poisson process, with parameter $\Lambda>0$. At the Poisson event for the second process, the household dies.

We focus on the general "health state" of an individual (rather than his/her medical status). Think of "health state" as referring to chronic conditions. Consider, for example, troubles with ADLs, as listed above. Individuals with such difficulties may need to hire assistance or move to a nursing home. The expense can be substantial. It may, in practice, be the largest part of average out-of-pocket (OOP) medical expenses (see, for instance, Marshall et al. [2010]).

We assume that health state affects behavior through state-dependent utility. In our framework, there are no direct budgetary consequences from changes in $h$. We treat all OOP medical expenses as part of consumption. A household with $h=H$ and consumption $c$ has utility flow

$$
u(c)=\frac{[c]^{\gamma}}{\gamma} .
$$

Following most empirical evidence, let

$$
\gamma<0
$$

We assume that health state $h=L$ leads to lower utility but higher marginal utility. Specifically, there is a household production technology for transforming expenditure, $x$, to a consumption service flow, $c$ :

$$
c=\left\{\begin{array}{ll}
x, & \text { if } h=H \\
\omega x, & \text { if } h=L
\end{array} .\right.
$$

We assume that low health state is an impediment to generating consumption services from $x$; thus,

$$
\omega \in(0,1) .
$$

Utility from consumption expenditure $x$ while in health state $h=L$ is

$$
\begin{gathered}
U(x) \equiv u(\omega \cdot x) \equiv \Omega \cdot u(x) \\
\Omega \equiv[\omega]^{\gamma}>1 .
\end{gathered}
$$

We assume that state verification problems for $h$ are much greater than for medical status. An agent knows when he/she enters state $h=L$, but the transition from $h=H$ is not 
legally verifiable. That prevents agents from obtaining health-state insurance. ${ }^{9}$ Marshall et al. write,

Indeed, the ultimate luxury good appears to be the ability to retain independence and remain in one's home ... through the use of (paid) helpers .... These types of expenses are generally not amenable to insurance coverage .... [p.26]

Annuities dependent upon health state are similarly unavailable. In contrast, all of our model's households have (Medicare) medical insurance. In reality, households also have access to means-tested public nursing home care provided through Medicaid. Medicaid nursing-home care is omitted here and receives detailed treatment in Laitner et al. [2013] (the discussion at the end of Section 4 provides a justification for analyzing the model with Medicaid separately).

Sections 3-6 assume that a household's annuity income is exogenously given. In practice, the most important annuities are Social Security and private pensions, both of which tend to determine annuity income by formula. Section 7 considers a household's optimal choice of initial annuitization. Section 8 also considers assistance from relatives - what is often labeled "informal care" — which we treat as an additional type of annuity. Our households cannot borrow against their annuity income.

Households can accumulate and decumulate liquid wealth. Bequeathable net worth, $b$, pays real interest rate $r>0$. Let $\beta \geq 0$ be the subjective discount rate. We assume $r \geq \beta$. If we think of the analysis as beginning at age 65, the average interval of $h=H$ might be about 12 years, and the average duration of $h=L$ about 3 years. ${ }^{10}$ With a Poisson process, average duration is the reciprocal of the hazard; hence, we assume $\Lambda>\lambda>r-\beta$.

State-Dependent Utility Our specification of household preferences assumes the simplest form of state-dependence: utility $u(x)$ in high health state and $\Omega u(x)$ in low health state, where $x$ is a single consumption category that includes OOP medical expenditure. ${ }^{11}$ This assumption is not as restrictive as one might think. In fact, a richer model where medical expenditure is a separate consumption category that is subject to choice would lead to an indirect utility function of the form (1). To see this, assume that a household has two remaining periods of life and that $h=H$ in the first period and $h=L$ in the last period. Set $r=0$ and $\beta=1$; disregard annuities, informal caregiving, and uncertain mortality. Then a newly retired household solves

$$
\max _{x}\{u(x)+U(b-x)\}
$$

To endogenize the choice of medical expenditure, $m$, replace $U(b-x)$ in $(3)$ with

$$
U(b-x) \equiv \kappa \cdot \max _{m}\{\varphi \cdot u(b-x-m)+(1-\varphi) \cdot u(m)\},
$$

\footnotetext{
${ }^{9} \mathrm{On}$ the use of long-term care insurance, which is analogous to health-state insurance in our model, see Miller et al. [2010], Brown and Finkelstein [2007, 2008], Brown et al. [2012], CBO [2004], and Pauly [1990]. Private insurance covers less than $5 \%$ of long-term care expenditures in the US (Brown and Finkelstein [2007]). For a discussion of information problems and the long-term care insurance market, see, for example, Norton [2000].

${ }^{10}$ E.g., Sinclair and Smetters [2004].

${ }^{11}$ Hubbard et al. [1995] and DeNardi et al. [2010] use similar specification of preferences but assume that OOP medical expenditure does not produce utility.
} 
where $\kappa>0$ and $\varphi \in(0,1)$ are preference parameters. ${ }^{12}$ Maximization with respect to $m$ in (4) yields exactly the reduced form utility function (1):

$$
\begin{gathered}
U(b-x)=\Omega \cdot u(b-x), \\
\Omega \equiv \kappa \cdot\left([\varphi]^{\frac{1}{1-\gamma}}+[1-\varphi]^{\frac{1}{1-\gamma}}\right) .
\end{gathered}
$$

Summary Recapping our baseline assumptions:

a1: "Health state" is not verifiable; hence, there is no health-state insurance. Annuities are exogenously set at retirement.

a2:If $b_{s}$ is bequeathable net worth when $h=H$ and $B_{s}$ is the same for $h=L$, we have $b_{s} \geq 0$ and $B_{s} \geq 0$ all $s \geq 0$.

a3: $\gamma<0, \omega \in(0,1)$, and $\Omega>1$.

a4: A household transitions from $h=H$ to $h=L$ with Poisson hazard $\lambda$, and from health state $h=L$ to death with Poisson hazard $\Lambda$. No other transitions have positive probability. We assume $\Lambda>\lambda$.

a5: The real interest rate is $r$, with $0 \leq \beta \leq r<\lambda+\beta$.

The model has two post-retirement timing uncertainties: How long does good health state last? How long does life last once low health state begins? Assumption a1 captures the second-best environment where individuals cannot perfectly insure these risks. In the firstbest environment with perfect insurance and annuity markets, the solution to the model is simpler, and it is well known (e.g. Yaari [1965]). The first-best solution involves a purchase of long-term care insurance and full annuitization: (i) At retirement, the agent buys an annuity paying a fixed benefit stream for the duration of high health state. (ii) At retirement, an agent also buys an insurance policy paying a lump-sum benefit when the agent's high health state ends. We refer to this as "long-term care insurance" — since it pays off exactly when the agent begins to have extra consumption needs. (iii) Agent uses his/her insurance payout to buy an annuity on his/her life. The payout stream from the latter annuity begins as low health state commences. All financial transactions can be completed at the moment of retirement, and retirees choose not to hold any liquid wealth.

Information asymmetries and state verification difficulties prevent the first-best outcome in practice. Agents may have private information about their $\lambda$ and $\Lambda$. This might include knowledge of "pre-existing conditions," etc. Agents waiting until years after retirement to purchase long-term care insurance will tend to attract special scrutiny in this regard: insurers may suspect that such an agent realizes he/she faces an imminent health change. For their part, agents may worry about a long-term care insurers' willingness to pay claims, and to pay promptly, when low health state arrives. Often a long-term care policy will have a payout taking the form of a secondary annuity providing an income flow for the duration of low health state. In that case, an insurer has incentive to delay a long-term care policy's payoff, and state verification difficulties may provide an excuse.

\section{Low Health Phase}

We solve our model backward, beginning with the last phase of life when the household is in the low health state $h=L$. In its last phase, a household faces mortality hazard $\Lambda$. Without

\footnotetext{
${ }^{12}$ Finkelstein et al. [2012] use preference specification similar to (4).
} 
loss of generality, scale the age at which the $h=L$ state begins to $s=0$. At $s=0$, let bequeathable net worth be $B \geq 0$. Annuity income is $a \geq 0, X_{s}$ is consumption expenditure at age $s$, and $U\left(X_{s}\right)$ the corresponding utility flow. The expected utility of the household is

$$
\int_{0}^{\infty} \Lambda e^{-\Lambda \cdot S} \int_{0}^{S} e^{-\beta s} U\left(X_{s}\right) d s d S=\int_{0}^{\infty} e^{-\Lambda s} e^{-\beta s} U\left(X_{s}\right) d s
$$

The household maximization problem is

$$
\begin{gathered}
V(a, B) \equiv \max _{X_{s}} \int_{0}^{\infty} e^{-(\Lambda+\beta) s} U\left(X_{s}\right) d s \\
\text { subject to } \dot{B}_{s}=r \cdot B_{s}+a-X_{s}, \\
B_{s} \geq 0 \quad \text { all } s \geq 0, \\
B_{0}=B \text { and } a \text { given. }
\end{gathered}
$$

Disregarding the state-variable constraint $B_{s} \geq 0$ for the moment, the present-value Hamiltonian for (5) is

$$
\mathcal{H} \equiv e^{-(\Lambda+\beta) s} U\left(X_{s}\right)+M_{s} r\left(B_{s}+a-X\right)_{s},
$$

with costate $M_{s}$. We have the first-order condition

$$
\frac{\partial \mathcal{H}}{\partial X_{s}}=0 \Longleftrightarrow e^{-(\Lambda+\beta) s} U^{\prime}\left(X_{s}\right)=M_{s}
$$

and costate equation

$$
\dot{M}_{s}=-\frac{\partial \mathcal{H}}{\partial B_{s}} \Longleftrightarrow \dot{M}_{s}=-r \cdot M_{s}
$$

Substituting (6) into (7),

$$
\begin{gathered}
-(\Lambda+\beta) e^{-(\Lambda+\beta) s} U^{\prime}\left(X_{s}\right)+e^{-(\Lambda+\beta) s} U^{\prime \prime}\left(X_{s}\right) \dot{X}_{s}= \\
\dot{M}_{s}=-r \cdot M_{s}=-r e^{-(\Lambda+\beta) s} U^{\prime}\left(X_{s}\right) \Leftrightarrow \\
(\gamma-1) \frac{\dot{X}_{s}}{X_{s}}=-(r-(\Lambda+\beta)) \Leftrightarrow \\
\frac{\dot{X}_{s}}{X_{s}}=\sigma, \text { where } \sigma=\frac{r-(\Lambda+\beta)}{1-\gamma} .
\end{gathered}
$$

By assumption (a5), $\sigma<0$.

Consider Figure 1. Each dotted curve is a trajectory satisfying the budget constraint and (8). Eq. (8) shows that along each, $X_{s}>0$ all $s$. Hence, $\lim _{s \rightarrow \infty} B_{s}=\infty$.

Our first-order conditions would be sufficient for optimality if the transversality condition

$$
\lim _{s \rightarrow \infty} M_{s} \cdot B_{s}=0
$$

held. It is easy to see that it cannot: moving along any trajectory in Figure 1, upon reaching $X_{s}=a$, say, at $s=T$, set $X_{s}=a$ all subsequent $s$; then the modified trajectory is feasible, and it supplies higher consumption at times past $T$ than the figure's trajectories.

Nevertheless, Figure 1 hints at the form of the actual solution. We have 


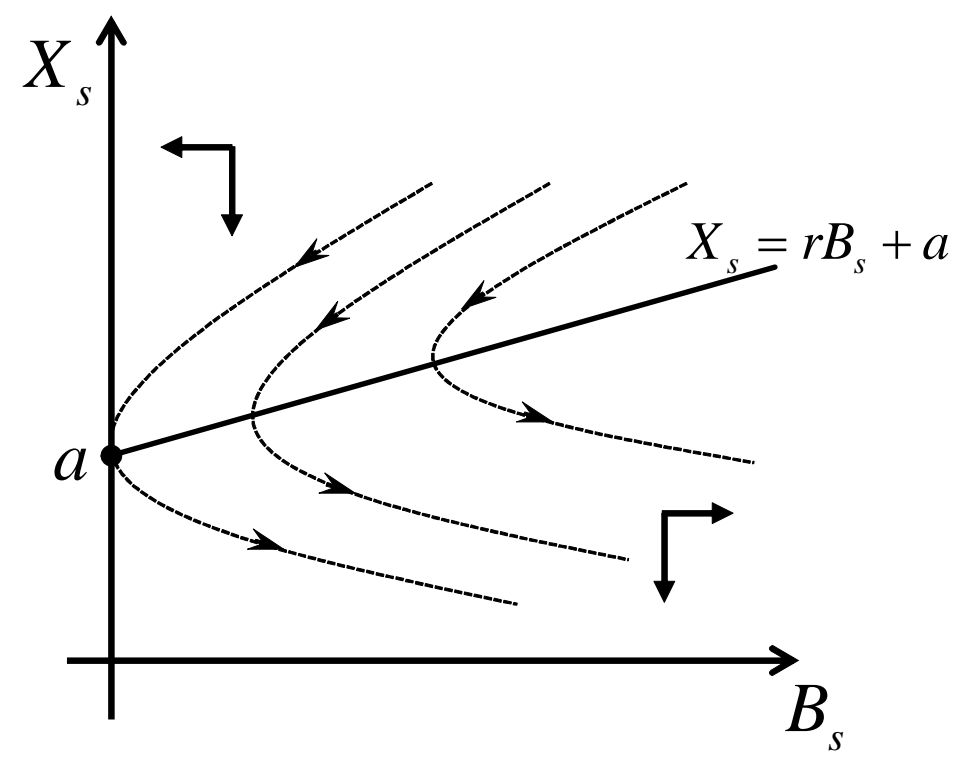

Figure 1: Trajectories satisfying the budget constraint and (8).

Proposition 1: For any $T \geq 0,\left(B_{t}, X_{t}\right)=(0, a)$ is a stationary solution for

$$
\begin{gathered}
\max _{X_{s}} \int_{T}^{\infty} e^{-(\Lambda+\beta) s} U\left(X_{s}\right) d s \\
\text { subject to }: \quad \dot{B}_{s}=r B_{s}+a-X_{s}, \\
B_{s} \geq 0, \\
a>0 \quad \text { and } B_{T}=0 \text { given. }
\end{gathered}
$$

The maximized criterion is

$$
W(a, T) \equiv e^{-(\Lambda+\beta) T} \frac{U(a)}{\Lambda+\beta} .
$$

Proof: See Appendix.

We can form a solution to (5) using Proposition 1.

Proposition 2: The trajectory in Figure 1 that reaches $\left(B_{s}, X_{s}\right)=(0, a)$ from above and then remains at $(0, a)$ forever solves problem (5).

Proof: See Appendix.

Knowing the form of the solution, we provide constructive steps to compute it by reformulating (5) to a free endpoint problem (e.g., Kamien and Schwartz [1991]):

Proposition 3: We have

$$
\begin{gathered}
V(a, B) \equiv \max _{X_{s}, T}\left(\int_{0}^{T} e^{-(\Lambda+\beta) s} U\left(X_{s}\right) d s+W(a, T)\right) \\
\text { subject to: } \dot{B}_{s}=r B_{s}+a-X_{s},
\end{gathered}
$$



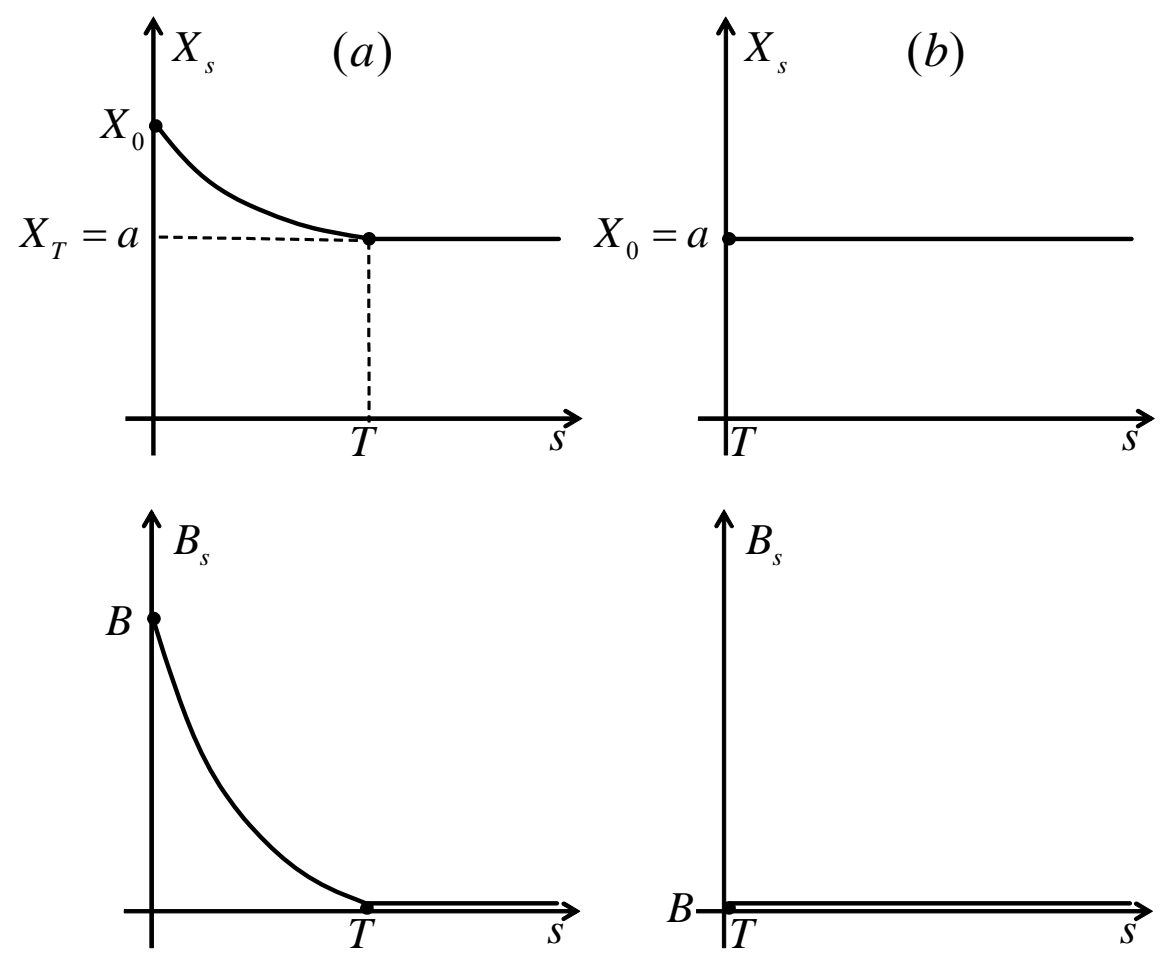

Figure 2: Optimal consumption and wealth trajectories in low health state. Panel (a) $B>0$, Panel (b), $B=0$.

$$
a \quad \text { and } \quad B_{0}=B \text { given. }
$$

$A$ solution to (10) exists with $B_{s} \geq 0$ all $s \geq 0, T<\infty, B_{T}=0$, and

$$
X_{s}=X_{0} e^{\sigma s} \quad \text { all } \quad s \in[0, T] .
$$

The initial consumption $X_{0}(a, B)$ is continuous, strictly increasing, and strictly concave in $B$ with

$$
\begin{gathered}
X_{0}(a, 0)=a, \\
\frac{\partial X_{0}(a, B)}{\partial B}=\frac{1}{\int_{0}^{T(a, B)} e^{-(r-\sigma) s} d s} \\
\lim _{B \rightarrow \infty} \frac{\partial X_{0}(a, B)}{\partial B}=r-\sigma .
\end{gathered}
$$

Proof: See Appendix.

Because $T=T(a, B)<\infty$, all households with sufficient longevity eventually subsist exclusively on their annuity income. That is to say, they become "liquidity constrained." The optimal length of liquidity-unconstrained period, $T$, rises with the initial wealth $B$. Figure 2 illustrates the optimal solution trajectory for the last phase of life.

Summary Our analysis shows that in their last phase of life, households systematically decumulate their bequeathable net worth and exhaust it within finite time. Thereafter they are "liquidity constrained," living exclusively on their annuity income. 


\section{High Health State Phase}

Turn next to households in the healthy phase of their retirement, where $h=H$. For convenience, rescale household ages to $s=0$ at the start of this phase. A household's annuity income is $a>0$ - which, as in the preceding section, we assume is exogenously given and its initial bequeathable net worth is $b \geq 0$.

The household's expected utility for its remaining life span is

$$
v(a, b)=\max _{x_{s}}\left(\int_{0}^{\infty} \lambda e^{-\lambda S}\left[\int_{0}^{S} e^{-\beta s} u\left(x_{s}\right) d s+e^{-\beta S} V\left(a, b_{S}\right)\right] d S\right) .
$$

The function $V(\cdot, \cdot)$ comes from Section 3 .

Changing the order of integration in the criterion of (14), we have our household healthy phase maximization problem:

$$
\begin{gathered}
v(a, b)=\max _{x_{s}}\left(\int_{0}^{\infty} e^{-(\lambda+\beta) s}\left[u\left(x_{s}\right)+\lambda V\left(a, b_{s}\right)\right] d s\right), \\
\text { subject to: } \dot{b}_{s}=r \cdot b_{s}+a-x_{s}, \\
b_{s} \geq 0 \quad \text { all } s \geq 0, \\
a \text { and } b_{0}=b \text { given. }
\end{gathered}
$$

Section 3 shows that $V(\cdot, \cdot)$ is concave in $B$; hence, the criterion integrand of $(15)$ is concave in $\left(x_{s}, b_{s}\right)$.

Disregarding the state-variable constraint $b_{s} \geq 0$ for the moment, the present-value Hamiltonian is

$$
\mathcal{H} \equiv e^{-(\lambda+\beta) t}\left[u\left(x_{s}\right)+\lambda V\left(a, b_{s}\right)\right]+\mu_{s}\left[r b_{s}+a-x_{s}\right]
$$

with $\mu_{s}$ as the costate variable. The first-order condition for $x_{s}$ is

$$
\frac{\partial \mathcal{H}}{\partial x_{s}}=0 \Longleftrightarrow e^{-(\lambda+\beta) s} u^{\prime}\left(x_{s}\right)=\mu_{s}
$$

The costate equation is

$$
\dot{\mu}_{s}=-\frac{\partial \mathcal{H}}{\partial x_{s}}=-e^{-(\lambda+\beta) s} \lambda \frac{\partial V\left(a, b_{s}\right)}{\partial b_{s}}-r \mu_{s} .
$$

The budget equation is

$$
\dot{b}_{s}=r b_{s}+a-x_{s}
$$

We now construct a phase diagram for $\left(b_{s}, x_{s}\right)$. Let $X_{0}\left(a, b_{s}\right)$ be the initial consumption for the household entering the low health state at date $s$ with wealth $b_{s}$ and annuity income $a$. The envelope theorem shows

$$
\frac{\partial V\left(a, b_{s}\right)}{\partial b_{s}}=U^{\prime}\left(X_{0}\left(a, b_{s}\right)\right)=\Omega u^{\prime}\left(X_{0}\left(a, b_{s}\right)\right)
$$

Eqs (16)-(20) imply

$$
u^{\prime \prime}\left(x_{s}\right) \dot{x}_{s}=-(r-(\lambda+\beta)) u^{\prime}\left(x_{s}\right)-\lambda \Omega u^{\prime}\left(X_{0}\left(a, b_{s}\right)\right) \Leftrightarrow
$$




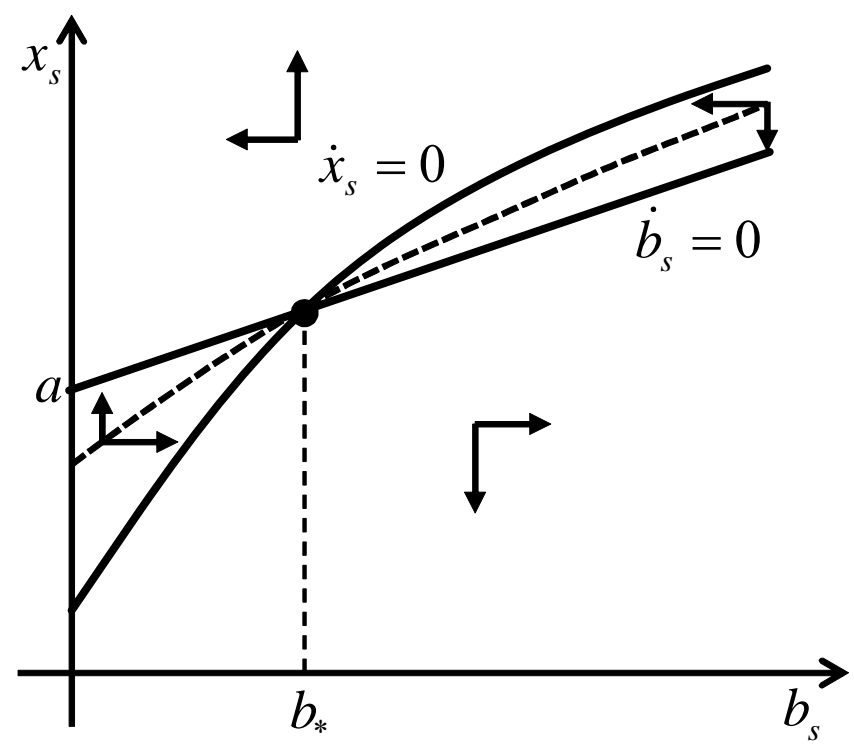

Figure 3: Phase diagram for the optimal solution to (15): baseline variant.

$$
\dot{x}_{s}=-(r-(\lambda+\beta)) \frac{u^{\prime}\left(x_{s}\right)}{u^{\prime \prime}\left(x_{s}\right)}-\lambda \Omega \frac{u^{\prime}\left(X_{0}\left(a, b_{s}\right)\right)}{u^{\prime \prime}\left(x_{s}\right)}
$$

Eqs (19) and (21) determine the phase diagram.

The equations for the isoclines of the phase diagram are

$$
\begin{gathered}
\dot{b}=0: \quad x_{s}=\Gamma^{1}\left(b_{s}\right) \equiv r b_{s}+a, \\
\dot{x}=0: \quad x_{s}=\Gamma^{2}\left(b_{s}\right) \equiv \theta X_{0}\left(a, b_{s}\right),
\end{gathered}
$$

where

$$
\theta \equiv\left(\frac{\lambda-(r-\beta)}{\lambda \cdot \Omega}\right)^{\frac{1}{1-\gamma}} \in(0,1) .
$$

Proposition 3 shows that $\Gamma^{2}(0)=\theta \cdot X_{0}(a, 0)=\theta \cdot a<a$ and that $\Gamma^{2}($.$) is strictly concave.$ We can also show that the isoclines cross at most once. Hence, the phase diagram must be as in Figure 3 or 4 . We have

Proposition 4: The dotted trajectories of Figures 3-4 are the solutions for (15).

Proof: See Appendix.

THE EFFECT OF THE INTEREST RATE ON THE SOLUTION In most of our numerical examples below, Figure 3 is the outcome. The phase diagram of Figure 3 obtains when $r$ is below a threshold. To see this, recall that Proposition 3 shows the asymptotic slope of $\Gamma^{2}(b)$ is $\theta \cdot(r-\sigma)$. The slope of $\Gamma^{1}(b)$ is $r$. When $r=0, \Gamma^{2}(b)$ is asymptotically steeper than $\Gamma^{1}(b)$, so we have Figure 3. When $r=\lambda+\beta$, the asymptotic slope of $\Gamma^{2}(b)$ is zero, giving rise to Figure 4. It can also be shown that the difference in asymptotic slopes, $\theta \cdot(r-\sigma)-r$, falls monotonically in $r$. Hence, a high (low) interest rate tends to lead to Figure 4 (Figure 3).

Intuitively, given $\gamma<0$, a household has a strong desire to smooth its consumption service flow $c$. Accordingly, a household wants to increase its consumption expenditure when its health state changes from high to low. Bequeathable assets provide flexibility to do 


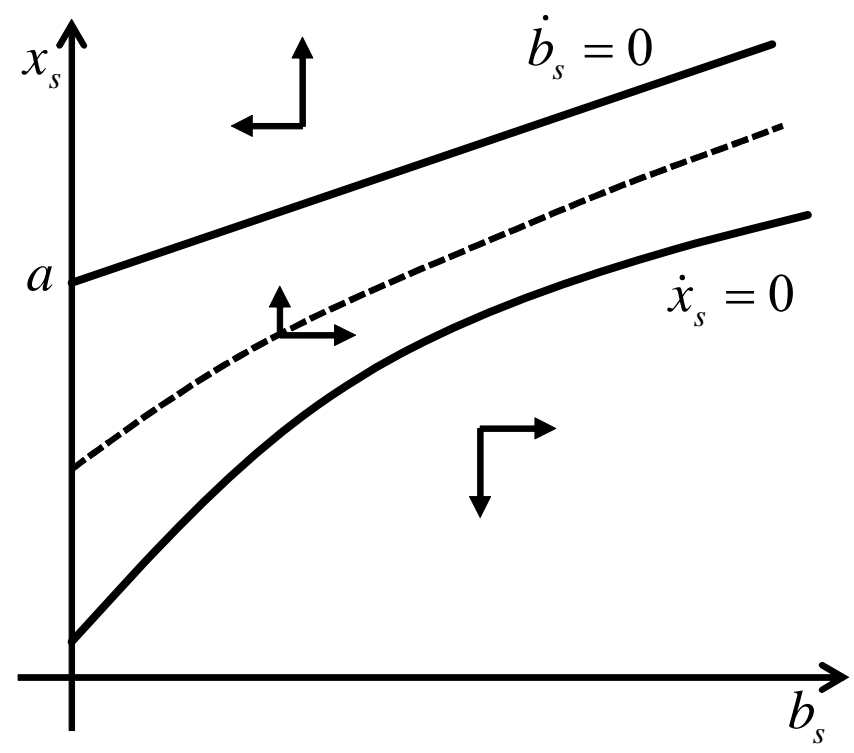

Figure 4: Phase diagram for the optimal solution to (15): possible variant.

so. A household can spend the principal of its bequeathable wealth after its health declines, for instance - recall Section 3.

While it may be beneficial for a healthy household to hold liquid wealth in anticipation of the low health state, the costs of maintaining this wealth depend on the interest rate $r$. If $r$ is high, liquid wealth is an attractive investment. At first, the household may desire more liquid wealth in preparation for poor health. As it adds to $b_{s}$, its interest income rises significantly. Even if the household raises its current consumption, it saves a portion of the new income to increase its low-health-state consumption in step. With Figure 4, saving continues as long as high health status lasts.

If, on the other hand, $r$ is more modest, we have Figure 3. A healthy household needs to sacrifice more current consumption to maintain or increase its stock of wealth. The incentive to accumulate wealth is therefore weakened, and the household is willing to accumulate more only if its current wealth level is below $b_{*}$.

The precise trade-off between current and future consumption is captured by the optimality condition (21). Evaluating the signs of the RHS and LHS of (21) yields

$$
\operatorname{sign}\{\dot{b}\}=\operatorname{sign}\{\dot{x}\}=\operatorname{sign}\left\{\lambda U^{\prime}\left(X_{0}\left(a, b_{s}\right)\right)-(\lambda+\beta-r) u^{\prime}\left(x_{s}\right)\right\} \text {. }
$$

Condition (25) shows that wealth accumulation/decumulation depends on the weighted difference between marginal utilities in the low and high health states. Notice that a lower interest rate increases the weight on the current marginal utility, $u^{\prime}\left(x_{s}\right)$, which dampens the incentive to accumulate.

DyNAmiCs Section 6 studies the set of initial conditions that lead to wealth accumulation during the healthy phase. It will be convenient to make a transformation of state variables that makes the model's dynamics dependent on a univariate ratio of initial conditions alone. The next proposition shows that our model is homothetic, making the optimal consumption expenditure linearly homogeneous in $(a, b)$.

Proposition 5: $\quad$ Let $X_{t}(a, B)$ be the optimal solution to problem (10) from initial condition 
$(a, B)$ and let $x_{t}(a, b)$ be the optimal solution to problem (15) from initial condition $(a, b)$. Then for any $a>0, B \geq 0$ and $b \geq 0$

$$
\begin{gathered}
X_{t}(a, B)=a X_{t}\left(1, \frac{B}{a}\right), V(a, B)=a^{\gamma} V\left(1, \frac{B}{a}\right), \\
x_{t}(a, b)=a x_{t}\left(1, \frac{b}{a}\right), v(a, b)=a^{\gamma} v\left(1, \frac{b}{a}\right) .
\end{gathered}
$$

Proof: See Appendix.

We can therefore summarize the wealth dynamics with the behavior of the transformed variable

$$
z_{t}=\frac{b_{t} R_{A}}{a}
$$

which equals to the ratio of bequeathable wealth to the annuitized wealth (capitalized at the actuarially fair rate $R_{A}$ ). ${ }^{13}$ Put differently, the saving rate (out of total wealth) in our model depends only on portfolio composition and not on the household's amount of total resources. The following corollary states that wealth accumulation in healthy state obtains if and only if $z$, the initial ratio of bequeathable wealth to the annuitized wealth, is below a threshold.

Corollary to Proposition 5 Suppose that the exogenous parameters correspond to phase diagram Figure 3. Then the long-run ratio of bequeathable to annuitized wealth

$$
z_{*}=\frac{b_{*} R_{A}}{a}
$$

does not depend on a. Optimal solution to (15) entails wealth accumulation if and only if $z<z_{*}$.

Portfolio composition and wealth accumulation. The above Corollary illustrates the key role that portfolio composition plays in wealth accumulation behavior. Our baseline model assumes annuity income is exogenously set at retirement. We are thinking of "primary annuities," such as Social Security and DB pensions. For middle class families, compulsory participation may lead to a significant share of annuitized wealth in their portfolio. Households that are heavily annuitized at retirement have low initial $z$, and they are the ones that will continue saving after retirement. Moreover, the maximum amount of wealth that a household is willing to accumulate is proportionate to $a$, making annuitized and bequeathable wealth function as complements. To see if the model would predict wealth accumulation/decumulation, one just needs to compare the initial $z$ ratio (to be taken from the data) with the target ratio $z_{*}$ implied by the model. The next section calibrates the model and numerically evaluates $z_{*}$.

The effect of means tested Public assistance Before turning to calibrations, we digress briefly to consider the possible consequences of Medicaid provided nursing home care (see Laitner et al. [2013] for details). One can model public assistance as providing a

${ }^{13}$ The actuarially fair rate is based on population average mortality profile and is equal to

$$
R_{A}=\frac{(\lambda+r)(\Lambda+r)}{\Lambda+\lambda+r}
$$

See the Appendix for the derivation. 
low health household with a utility floor $\underline{U}$ for the duration of its remaining life. The means test requires households to forfeit all wealth (including annuities) before obtaining utility flow $\underline{U}$. Accordingly, household flow utility in problem (5) becomes $\max \{\underline{U}, U(X)\}$.

Households with annuity income affording utility flow $U(a) \geq \underline{U}$ will disregard Medicaid completely and behave as in the basic model of this paper. It is likely that this group will be large in practice, because $\underline{U}$ may be low, a phenomenon labeled "public care aversion" ${ }^{14}$ On the other hand, households with $U(a)<\underline{U}$ and low total wealth will preemptively decumulate wealth in order to qualify for benefits. The behavior of this low-resource group can differ substantially from the basic model's predictions. Households in the midrange of lifetime resources may use Medicaid as a backup, but will still want to accumulate wealth to try to avoid Medicaid, or at least postpone it. For the midrange group, annuities would tend to be especially unattractive because of their treatment in the Medicaid means test.

\section{Calibration and Numerical Examples}

Our model has a limited number of parameters. Set $\lambda=0.0833$ and $\Lambda=0.3333$, corresponding to time intervals of 12 and 3 years, respectively, as in Sinclair and Smetters [2004]. The literature has a variety of estimates of $\gamma \leq 0$ (see, for example, Laitner and Silverman [2012]) and generally uses $\beta \in[0,0.04]$. We consider $\gamma \in[-0.5,-5.0], r \in[0.02,0.04]$ and set $\beta=0.02$.

A key parameter in our model is $\omega$, giving the degree to which the marginal utility of consumption expenditure rises with low health state. The interpretation of $\omega$ depends, in fact, upon $\gamma$. Marginal utility in good health is $u^{\prime}(x)$ when consumption expenditure is $x$. In low health state, it is

$$
U^{\prime}(x)=\frac{\partial u(\omega x)}{\partial x}=\omega u^{\prime}(\omega x)=u^{\prime}\left([\omega]^{\frac{\gamma}{\gamma-1}} x\right) .
$$

It is $[\omega]^{\frac{\gamma}{\gamma-1}}$ that determines the degree to which low health state affects a household's marginal utility from consumption expenditure. We can relate $[\omega]^{\frac{\gamma}{\gamma-1}}$ to the observable variables as follows. The change in optimal expenditure upon entering the low health state is directly related to the magnitude of $[\omega]^{\frac{\gamma}{\gamma-1}}$. To see this, assume that low health state occurs at time $t$ when liquid wealth is at its long-run optimal level $b_{t}=b_{*}$. Then (23) shows that at time $t$ the optimal expenditure jumps by a factor

$$
\frac{X_{0}\left(a, b_{*}\right)}{x_{t}\left(a, b_{*}\right)}=\frac{1}{\theta}>1
$$

For simplicity, set $r=\beta$. Then using (2) in expression (24) for $\theta$ and noting that consumption of healthy households equals income when $b_{t}=b_{*}$ shows that

$$
\frac{X_{0}\left(a, b_{*}\right)}{x_{t}\left(a, b_{*}\right)}=\frac{X_{0}\left(a, b_{*}\right)}{a+r b_{*}}=\frac{X_{*}}{x_{*}}=[\omega]^{\frac{\gamma}{1-\gamma}} .
$$

Comparing the cost of care in low health state to income of single retirees provides a way of calibrating $\omega$. Our model's low health state corresponds to a need for nursing-home levels of

\footnotetext{
${ }^{14}$ Ameriks et al. [2011] attempt to calibrate the perceived level of $\underline{U}$ from survey questions and find it to be commensurate with a consumption flow of just $\$ 2,200$ per year in 2005 dollars. In practice, only a minority of households utilize Medicaid assistance - see DeNardi et al. [2011].
} 
care. ${ }^{15}$ Prudential [2010] shows 2010 annual average expenditures for nursing-home care of $\$ 78,475$ for a semi-private room, and $\$ 90,155$ for a private room. ${ }^{16}$ Accordingly, we calibrate $X_{*}=80,000$. In terms of the denominator of (27), Bannerjee [2012, Table 7] reports the average income of about $\$ 22,000$ for single-person households over the age of 65 . Hence, we set $x_{*}=22,000$, and, using (27), we calibrate

$$
[\omega]^{\frac{\gamma}{1-\gamma}}=\frac{X_{*}}{x_{*}}=\frac{80,000}{22,000}=3.64 .
$$

For comparison purposes, our analysis examines cases with $[\omega]^{\frac{\gamma}{1-\gamma}}=3.0$ and 4.0 as well.

Calibration of initial Conditions Apart from the exogenous parameter values, wealth accumulation behavior depends on the initial condition $z$. To evaluate the model numerically, we need to find the counterpart of $z$ in the data. Table 1 reports components of wealth for single-person households from Poterba et al. [2011] and calculates the corresponding $z$ ratio. $^{17}$ The definition of consumption in our model includes medical expenditure, so the logic of the model dictates including capitalized Medicare flows as part of annuitized wealth. Our preferred range of initial conditions for $z$ is, therefore, the last column of Table 1.

Numerical EXAMPles Table 2 presents stationary values $z_{*}$ corresponding to various $\gamma$ and real interest rates $r$. When Figure 4 phase diagram applies, $z_{*}$ is infinite. Our favored calibration is $[\omega]^{\frac{\gamma}{1-\gamma}}=3.64$. In almost all cases, the range of initial conditions $z$ from Table 1 (last column) is well below $z_{*}$. The model predicts, in other words, that most households in the data have sufficient pre-annuitization to warrant subsequent accumulation of wealth. When $[\omega]^{\frac{\gamma}{1-\gamma}}=3.0$, similar results hold for $\gamma<-1.0$. Values of $z_{*}$ are even higher for $[\omega]^{\frac{\gamma}{1-\gamma}}=4.0$ - with Figure 4 phase diagram, where rising bequeathable wealth in good health is inevitable, appearing more often as well.

\section{Cohort wealth Trajectories}

Although the standard life-cycle model (Modigliani [1986]) implies that households should systematically dissave after retirement, survey data often reveals stationary or rising cohort mean bequeathable wealth. After briefly reviewing the literature below, we present our model's analysis.

Evidence Mirer [1979, p.442] was surprised to find that his data showed household accumulation of bequeathable wealth after retirement rather than dissaving. He concluded, "... the simple form of the life cycle theory of saving, in which wealth is accumulated during working years in order to finance consumption during retirement, is too simple." In the same vein, Kotlikoff and Summers [1988, p.54] write, "Decumulation of wealth after retirement is an essential aspect of the life cycle theory. Yet simple tabulations of wealth holdings by age ... or savings rates by age ... do not support the central prediction that the aged dissave." More recently, Ameriks et al. [2011, p.519] observe, "In reality, ... assets of the old decrease slowly if at all ...."

Although one might suspect that mortality selection would bias estimated post-retirement average wealth trajectories upward with age, evidence from panel data sets confirms the

\footnotetext{
${ }^{15}$ Recall that the calibration of $\Lambda$ is based on Sinclair and Smetters [2004, Table 3] survival probabilities for individuals in long-term care.

${ }^{16} \mathrm{http}: / /$ www.prudential.com/media/managed/LTCCostStudy.pdf

${ }^{17}$ Moments reported in Table 1 are for individual wealth components. The value of $z$ is the ratio of the corresponding moments.
} 
earlier findings. See, in particular, Poterba et al. [2011, Fig. 1.8-1.9]. Poterba et al. study single households and couples separately. They link average bequeathable wealth holdings in adjoining survey waves, including only households with data in both waves. Their procedure should be immune to birth-cohort effects and to correlations of survival probabilities with portfolio size. For either means or medians, their figures show stationary or rising-with-age trajectories of bequeathable wealth for both singles and couples. ${ }^{18}$

Post-Retirement Wealth Holdings In analyzing post-retirement cohort-average trajectories of bequeathable wealth, we divide a cohort's survivors into two groups, high and low health state households. We first show that the relative size of the groups converges to a limit. Secondly, we draw on Section 3 to explain behavior within each group. Finally, we show that the preceding factors together make stationary or rising cohort-average trajectories possible — and, indeed, likely given our parameter choices.

Relative Group Size. Although every household eventually falls to the low health state, the ratio of the sizes of the high and low-health-state groups converges to a positive constant. This outcome is less paradoxical that it might at first seem: as the healthy group continuously loses members to low health state, the low health group simultaneously loses members to mortality. The fraction of our model's households remaining alive and in good health $t$ years after retirement is

$$
f_{H}(t)=e^{-\lambda t}
$$

The fraction alive at $t$ but in low health state is

$$
f_{L}(t) \equiv \int_{0}^{t} \lambda \cdot e^{-\lambda \cdot s} \cdot e^{-\Lambda(t-s)} d s .
$$

Combining expressions, the fraction of survivors in high health state is

$$
f(t) \equiv \frac{f_{H}(t)}{f_{H}(t)+f_{L}(t)}=\frac{1}{1+\frac{\lambda}{\Lambda-\lambda} \cdot\left(1-e^{-(\Lambda-\lambda) \cdot t}\right)} .
$$

We can see that $f(0)=1.0$ and that $f(t)$ monotonically falls to $f(\infty)=(\Lambda-\lambda) / \Lambda$. The latter equals 0.75 for our values of $\lambda$ and $\Lambda$.

The convergence of $f(t)$ is important. Section 3 shows that low health state households always decumulate their bequeathable wealth. If the low health group became an ever larger fraction of its cohort, then the cohort's overall average bequeathable wealth would presumably eventually begin a permanent decline.

Cohort average wealth. Consider a cohort of one-person households beginning retirement in the high health state. There are $N$ households in the cohort at retirement, and there is a distribution of annuity flows $a$ among the households that has mean $\bar{a}$. For simplicity, assume that all households start with the same initial ratio of bequeathable to annuity wealth, $z$.

If Figure 3 phase diagram applies and all households begin retirement with the initial condition $z<z_{*}$, the aggregate wealth of healthy households should rise or be stationary. Let $b_{t}(a, b)$ be the optimal wealth trajectory in the high health state, where $t$ is the time since retirement. Proposition 5 shows that

$$
b_{t}(a, b)=a b_{t}\left(1, \frac{z}{R_{A}}\right)
$$

\footnotetext{
${ }^{18}$ See also Love et al. [2009], Poterba et al. [2011b], and Smith et al. [2009].
} 
Then the total wealth of healthy households $t$ periods after retirement is ${ }^{19}$

$$
b_{H}(t)=N \cdot \bar{a} \cdot e^{-\lambda t} \cdot b_{t}\left(1, \frac{z}{R_{A}}\right) .
$$

The total wealth of survivors in low health state depends on the age when their health changed. If the household enters the low health state $s \leq t$ periods after retirement, its initial wealth upon entering the low health state is $B=b_{s}(a, b)$, and it follows the lowhealth-state optimal wealth trajectory $B_{t-s}\left(a, b_{s}(a, b)\right)$ for $t-s$ periods. Using Proposition 5 again,

$$
B_{t-s}\left(a, b_{s}(a, b)\right)=a B_{t-s}\left(1, \frac{b_{s}(a, b)}{a}\right)=a B_{t-s}\left(1, b_{s}\left(1, \frac{z}{R_{A}}\right)\right) .
$$

The fraction of households entering low health state at age $s$ and surviving until age $t$ is $\lambda e^{-\lambda s} e^{-\Lambda(t-s)}$. Accordingly, the total wealth of survivors in the low health state $t$ periods after retirement is

$$
b_{L}(t)=N \cdot \bar{a} \cdot \int_{0}^{t} \lambda e^{-\lambda s} e^{-\Lambda(t-s)} B_{t-s}\left(1, b_{s}\left(1, \frac{z}{R_{A}}\right)\right) d s .
$$

The cohort average wealth level is the total wealth of survivors divided by the current cohort size:

$$
\bar{b}(t)=\frac{b_{H}(t)+b_{L}(t)}{f_{H}(t)+f_{L}(t)} .
$$

Figure 5 plots cohort average wealth relative to its initial level, $\bar{b}(t) / \bar{b}(0)$, for various values of initial condition $z$ consistent with Table 1 . Normalizing by $\bar{b}(0)$ eliminates any role for $\bar{a}$ or $N$. For the chosen exogenous parameters, $z_{*}=0.93$.

As the theoretical analysis shows, the model's cohort average bequeathable wealth can rise or fall with age depending on time-varying cohort composition and the behavior of the healthy. When $z=0.7$ in Figure 5, cohort average bequeathable wealth falls slightly at first as the size of the healthy group shrinks rapidly. However, it subsequently gently rises as group sizes stabilize and the wealth accumulation within the healthy group dominates other effects. $^{20}$ Thus, the accumulation behavior of healthy households eventually drives cohort average bequeathable wealth upward. On the other hand, wealth trajectories on Figures 5 demonstrate that our model makes rising average wealth after retirement a possibility, but not an inevitability.

Discussion Due to homotheticity (Proposition 5), the model does not predict any difference in saving rates by total wealth level. A richer setup featuring means-tested public assistance and bequest motives would likely generate different saving rates at different total wealth levels (e.g., Dynan et al. [2004], DeNardi et al. [2010]). Nevertheless, our analysis shows that cohort wealth trajectories that rise with age are possible even without additional modeling elements.

\footnotetext{
${ }^{19}$ Since the hazard rates $\lambda$ and $\Lambda$ are not correlated with $a$, the distribution of $a$ conditional on health state is the same as the unconditional distribution of $a$.

${ }^{20}$ Surviving healthy households asymptotically reach $z_{*}$ and the graphs eventually become horizontal. With the parameters of Figure 5, however, the half-life of convergence to $z_{*}$ is more than 25 years.
} 


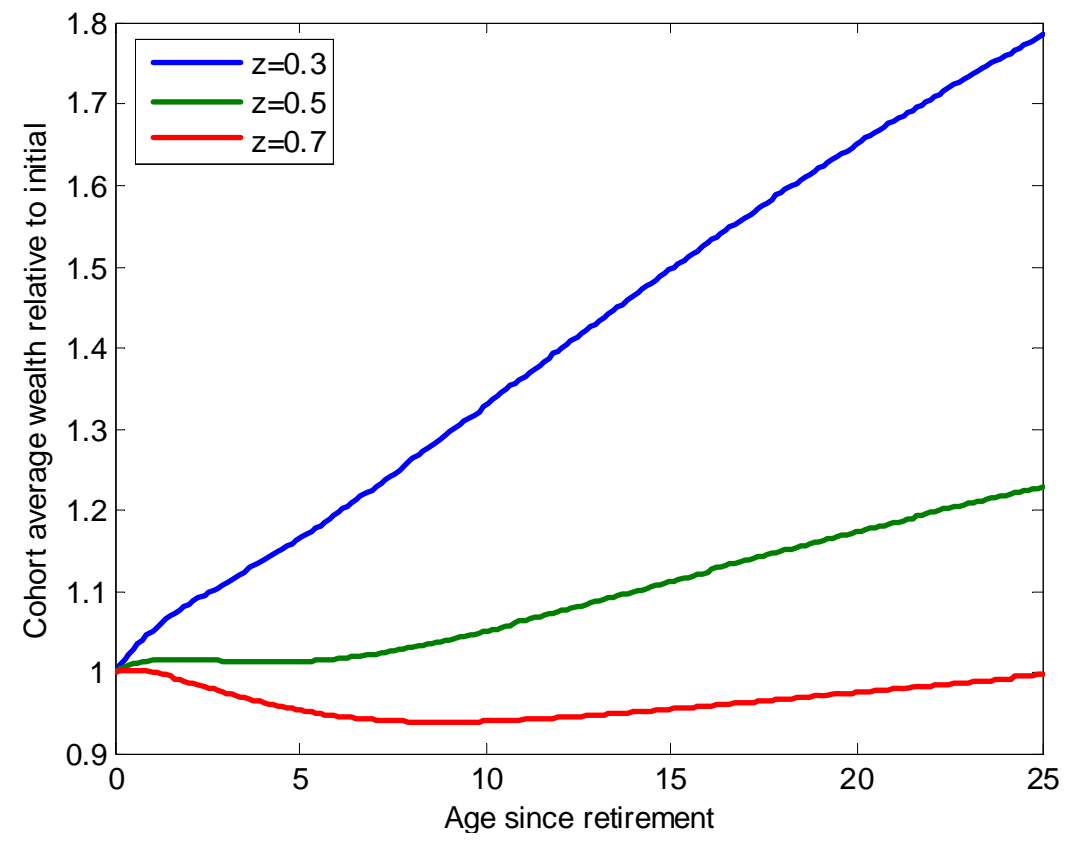

Figure 5: Cohort average wealth trajectories for different values of initial condition $z$. Other parameters: $\lambda=1 / 12, \Lambda=1 / 3, r=\beta=0.02, \gamma=-1, \omega^{\frac{\gamma}{1-\gamma}}=3.64$.

\section{Demand for Annuities}

The baseline model of Section 2 treats annuity income $a$ as exogenous, where $a$ reflects what we might call "primary annuities" - compulsory or default annuities such as Social Security, Medicare, and DB pension benefits. Due to wide participation, we think of primary annuities as offering actuarially fair rates of return. This section investigates circumstances under which our framework can be consistent with the observation that households rarely purchasing what we refer to as "secondary annuities." We take the latter to be market securities sold to individuals and often paying lower rates of return than primary annuities (because of adverse selection and transactions costs).

To perform this section's analysis, we extend our model to allow households to re-balance their portfolios at retirement. All households begin retirement in the healthy state, with value function $v(a, b)$. Let $R$ denote the market rate of return on secondary annuities. It is convenient to express $R$ as a fraction of the actuarially fair rate of return $R_{A}$ (recall Section 4):

$$
R=(1-\pi) R_{A}=(1-\pi) \frac{(\lambda+r)(\Lambda+r)}{\Lambda+\lambda+r},
$$

where $\pi$ is interpreted as annuity load. Let the choice variable $A$ denote the capitalized value of secondary annuities providing income flow $A R$. The household portfolio selection problem is

$$
\max _{A \in[0, b]} v(a+A R, b-A) .
$$

Let

$$
\begin{gathered}
a^{\prime}=a+A R, \\
b^{\prime}=b-A
\end{gathered}
$$


denote the corresponding optimal portfolio choice. After the portfolio selection, the household solves problem (15) from the resulting initial condition $\left(a^{\prime}, b^{\prime}\right)$.

The following proposition characterizes the solution to (29).

Proposition 6: The optimal solution to (29) is

$$
A=\max \left\{0, \alpha_{0} b-\left(1-\alpha_{0}\right) \frac{a}{R}\right\}
$$

where

$$
\alpha_{0}=\arg \max _{\alpha \in[0,1]} v\left(\alpha, \frac{1-\alpha}{R}\right) .
$$

The new initial condition for the household is

$$
z^{\prime}=\frac{b^{\prime} R_{A}}{a^{\prime}}=\min \left\{z, z_{0}\right\} \text { where } z_{0}=\frac{1-\alpha_{0}}{\alpha_{0}} \frac{1}{1-\pi} .
$$

Proof: See Appendix.

In Proposition 6, $\alpha_{0}$ corresponds to the unconstrained optimal fraction of annuitized wealth in the portfolio, given rate of return $R$. We assume households cannot reduce their stock of primary annuities. If the initial fraction of pre-annuitized wealth exceeds $\alpha_{0}$, the household does not purchase secondary annuities and sets $A=0$. Otherwise, however, the household selects the portfolio with the fraction of annuitized total net worth exactly equaling $\alpha_{0}$.

Subsequent household behavior depends upon $z^{\prime}$. The next proposition provides a sufficient condition for both continuing wealth accumulation post retirement and zero demand for secondary annuities at retirement:

Proposition 7: If the initial ratio of bequeathable wealth to annuitized wealth is below a threshold,

$$
z<\bar{z}=\min \left\{z_{0}, z_{*}\right\}
$$

then the optimal solution to (29), (15) has

$$
A=0 \text { and } \dot{b}_{t}>0, \text { all } t
$$

Proof: See Appendix.

We evaluate the threshold value of $\bar{z}$ numerically and compare it to the range of $z$ values from Table 1 to see if the model would predict both zero demand for secondary annuities and wealth accumulation after retirement. If $\pi=0$, households choose to fully annuitize all of their wealth (meaning $\alpha_{0}=1$ and $z^{\prime}=z_{0}=0$ ), and this contradicts the observations on household balance sheets in Table 1 . We ask if the model can produce both $A=0$ and $\dot{b}>0$ for annuity loads in the empirically observed range.

Calibration of Annuity LOAD. We calibrate the empirical load $\pi$ on secondary annuities from measures of the internal rate of return on commercially available products. Our riskless real interest rate is $r$. Suppose the internal rate of return on a secondary annuity is $r+\Delta r$. If $\Delta r<0$, then $\pi>0$. Expression (28) implies

$$
(1-\pi) R_{A}=R=\frac{(\lambda+r+\Delta r)(\Lambda+r+\Delta r)}{\Lambda+\lambda+r+\Delta r} .
$$

Using 1968-83 data, Friedman and Warshawsky [1990, Tab III] derive an internal rate of return on marketed annuities for 65-year-old men. They use two alternative definitions of $r$ : 
$r=r_{T}$, where $r_{T}$ is the yield to maturity on 20-year US government bonds, and $r=r_{C}$, where $r_{C}$ is the return on corporate debt directly placed with insurance companies. ${ }^{21}$ They report $\Delta r_{T}=-0.0421$ and $\Delta r_{C}=-0.0613$. They report $\Delta r_{T}=-0.0421$ and $\Delta r_{C}=-0.0613$. We can perform analogous calculations using 1995 data, averaged over men and women, reported in Mitchell et al. [1999, Table 4], including their $r_{T}$ and $r_{C}$ values (see their p.1311). Corresponding internal rate of return differentials are appreciably narrower, $\Delta r_{T}=-0.0221$ and $\Delta r_{C}=-0.0369$. (Mitchell et al. [1999, p.1312] speculate that cyclic variability of interest rates may be at least part of the explanation. $)^{22}$

Table 3 derives values of $\pi$ from (30) consistent with the preceding range of internal rates of return $r+\Delta r$. If $r$ is interpreted as the real rate of return on Treasuries, we might set $r=0.02$. Table 3 entries then suggest $\pi \in[0.22,0.42]$. If $r$ is interpreted as the real rate of return on corporate bonds, then we favor $r=0.04$ and $\pi \in[0.31,0.51]$. Table 4 presents numerical results.

Numerical Results Table 4 reports threshold values $\bar{z}$ from Proposition 7 . These should be compared with initial conditions $z \in[0.24,0.67]$ derived from Table 1 . According to Proposition 7, $z<\bar{z}$ guarantees that a household chooses $A=0$ and $\dot{b}_{t}>0$. Table 4 shows that our model produces $\bar{z}>z$ for various $r$ and $\pi=0.4$ - but that it is less successful for lower loads. Section 8 re-examines demand for secondary annuities in an environment where family members can enter into annuity-like contracts.

\section{Non-market Annuities and Bequests}

In practice, an elderly household - in particular, a household with high expenses due to poor health status - may derive assistance from its grown children or other relatives. See, for example, Kotlikoff and Spivak [1981], who suggest that relatives may be able to surmount stateverification difficulties to offer what we might call "non-market annuities;" Laitner [1988], who studies formulations with two-sided altruism in which grown children may provide intergenerational transfers to their parents; and, Cox [1987], who considers a model in which parents may purchase services from their grown children on attractive terms. This section adopts the Kotlikoff-Spivak formulation. ${ }^{23}$ Specifically, we assume that family-line members know an elderly household's health state and are willing to offer a non-market annuity to the household when it reaches the last stage of life.

For simplicity, assume that relatives offer elderly households in poor health an annuity paying the actuarially fair, conditional on status $h=L$, rate of return $r+\Lambda$. There need not be any transfer of utility; a mutually advantageous contract is possible (Kotlikoff and Spivak [1981]). In the past, shared living arrangements were common at the end of life - and remain so to a more limited extent recently (CBO [1988]). The "informal caregiving" that

\footnotetext{
${ }^{21}$ Although Friedman and Warshawsky [1990] use nominal rates of return, subtracting the rate of inflation from each leaves $\Delta r$ unaffected.

${ }^{22}$ A more detailed look at annuity yields by age and population group in Mitchell et al. [1999, Table 4] reveals notable regularities. In all cases, annuity yields are much higher for annuity purchasers compared to general population, consistent with adverse selection on mortality in the secondary annuity market. Importantly, annuity yield falls with annuitant's age, creating an incentive to purchase secondary annuities without delay. The last observation may justify our assumption that secondary annuity purchases only happen at retirement.

${ }^{23}$ Kotlikoff-Spivak [1981] can be interpreted as falling within the general category of "exchange models" — see, for example, Bernheim et al. [1985], Horioka [2000], Wang [2010] and others.
} 
AARP [2011] values at $\$ 450$ billion per year for the US in 2009 might also reflect family-line contracts in this vein.

Beyond relatives' access to information on each others health status, reasons that nonmarket annuities may be feasible within family lines include the following. (i) For non-market annuities, benefit obligations can often take the form of in-kind services rather than monetary outlays. Relatives may be more confident in promising time than money. (ii) The expected duration of poor health is relatively short. And, (iii) the pleasures an elderly household and relatives derive from time together may provide a joint product complementary with a non-market annuity's in-kind service flow.

More generally, an arrangement under which, for instance, an assisted-living facility offers an elderly individual lifetime care in return for a substantial up-front payment could fit the same framework. Long-term care insurance contracted at retirement leaves the issuer vulnerable to the client's private information on the likely duration of his/her good health - whereas a contract signed at the onset of poor health does not. Conversely, long-term care insurance leaves a customer potentially vulnerable to procrastination on the part of the issuer in state-verification processing after poor health begins - whereas purchase of a service contract at the onset of poor health may avoid delays.

ExTEnded MOdel If we allow a household to purchase a non-market annuity with return $r+\Lambda$ as soon as its health state reaches $h=L$, the household will, at that point, want to annuitize all of its bequeathable wealth. As in Yaari [1965], the household's optimal consumption expenditure will thereafter be level. Formally, we have

Proposition 8: A household reaching the low health state at time $t$ and offered an annuity with return $r+\Lambda$ at that point will want to annuitize all of its remaining bequeathable wealth. Thereafter its optimal consumption expenditure is stationary. If $V(a, B)$ is as in (5), remaining lifetime utility at the onset of low health status is now

$$
V(a+B \cdot(r+\Lambda), 0)=\frac{U(a+B \cdot(r+\Lambda))}{\Lambda+\beta} .
$$

Proof: See Appendix.

Given the proposition, we replace the $V(a, b)$ in $(15)$ with $V(a+B \cdot(r+\Lambda), 0)$. Instead of (15), a healthy household solves

$$
\begin{gathered}
\bar{v}(a, b)=\max _{x_{s}}\left(\int_{0}^{\infty} e^{-(\lambda+\beta) s}\left[u\left(x_{s}\right)+\lambda V\left(a+b_{s} \cdot(r+\Lambda), 0\right)\right] d s\right), \\
\text { subject to: } \dot{b}_{s}=r \cdot b_{s}+a-x_{s} \\
b_{s} \geq 0 \quad \text { all } s \geq 0 \\
a \text { and } \quad b_{0}=b \text { given. }
\end{gathered}
$$

Demand for Secondary Annuities Given the availability of non-market annuities, initial portfolio choice problem $(29)$ has an objective function $\bar{v}(\cdot, \cdot)$ from $(32)$ in place of $v(\cdot, \cdot)$. Table 5 presents numerical results.

In all of our examples, the possibility of purchasing a non-market annuity entirely eliminates the demand for secondary annuities regardless of their load (i.e., for any $\pi \geq 0$ ). Table 5 presents the threshold values $\bar{z}$ corresponding to value function $\bar{v}(\cdot, \cdot)$, setting $\pi=0$. With no-load secondary annuities, the solution to portfolio choice problem (29) for every entry in Table 5 has $z_{0} \geq z_{*}$, so that $\bar{z}=z_{*} \leq z_{0}$. Hence, throughout Table 5 , households with 
$z \leq z_{*}$ exhibit no demand for secondary annuities at retirement — or thereafter. ${ }^{24}$ Table 1 suggests starting values $z \in[0.24,0.67]$. Given $z$ in that range, for all Table 5 columns other than perhaps $[\omega]^{\frac{\gamma}{1-\gamma}}=3.00$ and $r=0.02$, Proposition 7 implies both $A=0$ and subsequent liquid asset accumulation while good health persists.

We can go further. For starting values $z \in[0.24,0.67]$, every column of Table 5 except the one singled out above implies that households will be dissatisfied even with their primary annuities - just-retired households would prefer non-marginal reallocations of their initial net worth from primary annuities to liquid assets. A practical manifestation of the latter may be household reluctance to delay claiming their Social Security retirement benefits to secure greater annuitization (Sass [2012], GAO [2014]) ${ }^{25}$ In other words, our model provides a possible rationale for early claiming.

One way of thinking about why our non-market annuities tend to severely limit the demand for other annuities is as follows. A market annuity purchased during good health suffers a capital loss at the onset of poor health, just when a household's marginal utility of expenditure rises. An actuarially fair annuity purchased once low health status has begun pays return $r+\Lambda$ until the purchaser's death, and its value remains constant. In contrast, an annuity purchased while in good health for $\$ 1$ is worth $\$ 1$ until the onset of poor health, at which point its value abruptly drops to $\$ 1 \cdot \frac{R_{A}}{r+\Lambda}$. With our parameter values, the capital loss is about $75 \%$.

Post-retirement SAving in the extended model. The presence of non-market annuities affects the overall wealth accumulation of healthy households. To gauge the effect, compare $\bar{z}=z_{*}$ from Table 5 with the corresponding entries of Table 2 . We find that the availability of non-market annuities can either encourage or discourage post-retirement wealth accumulation relative to the basic model, depending on the risk aversion parameter $1-\gamma$. Households with a high intertemporal elasticity of substitution (low risk aversion) have a higher $z_{*}$ when non-market annuities are available. Such households anticipate a favorable investment opportunity (i.e. a family-line annuity with return $r+\Lambda$ ) upon reaching the low health state, and this encourages wealth accumulation while healthy. Households with a high degree of risk aversion, on the other hand, have a lower $z_{*}$ when non-market annuities are available. Evidently, very risk-averse individuals find protection against outliving their resources so reassuring that they are comfortable saving less in total. For the same reason, the Figure 4 phase diagram becomes less likely - never, in fact, arising in Table 5.

BEQUESTS Given households' reluctance to fully annuitize their portfolios, one would expect that virtually all would leave an accidental bequest. Yet, in practice, bequests are relatively rare. Laitner and Ohlsson [2001], for example, find a middle-class frequency of inheritance of 30-40\% in PSID data; Laitner and Sonnega [2010, 2012] find a frequency of $20-40 \%$ in HRS data. The relative scarcity of bequests in the presence of end-of-life wealth holding and thin annuitization is puzzling. Adding a bequest motive to the model would only exacerbate the puzzle. The extended model with non-market annuities offers a possible explanation.

To illustrate the extent of the bequest puzzle, Table 6 reports the frequency of positive bequests from our baseline model (Sections 2-6), and the frequency of bequests exceeding

\footnotetext{
${ }^{24}$ Chances to purchase extra annuities may diminish with age after retirement because of issuer worries about adverse selection - recall Section 7, footnote 22. Nevertheless, in Table 5, non-market annuities eliminate demand for more secondary (or primary) annuities at all post-retirement ages.

${ }^{25}$ Notice that in our model, delaying Social Security claiming leads, in effect, to full reinvestment in primary annuities of benefits deferred during the period of delay.
} 
a year's annuity income $a .^{26}$ In all cases, accidental bequest frequencies are too high to be consistent with US data.

A model with family line annuities may provide a way to reconcile the predicted frequency of accidental bequests with the much lower inheritance frequency found in the data. If a household purchases a family-line annuity, it makes an inter-vivos transfer to the caregiver relative and leaves no bequest (Proposition 8). One testable implication of the model is that inter-vivos transfers, but not bequests, should be positively correlated with the amount of help that the elderly receive from their children. A recent study by Wang [2010] using HRS data provides supportive evidence. Wang [2010] writes: "Results from national data show that adult children's time transfers to their aging parents were positively associated with their expectation of inter-vivos financial transfers, but not with their expectation of receiving bequests".

We might then interpret inheritance data as follows: (i) measured bequests may reflect intentional behavior, beyond the scope of this paper's analysis; (ii) perhaps not all elderly households can, or desire to ask their relatives for non-market annuities; and/or, (iii) survey respondents may incorrectly classify some payments for services from relatives as bequests. If, for example, one-half to one-third of elderly households do not use family-line annuities, the bequest puzzle could be resolved. Or, perhaps family-line assistance is very widespread - but some households choose to leave intentional bequests.

SUMmaRY In an environment with complete markets, households would purchase an assortment of annuities and long-term-care insurance at retirement, but would choose to hold no bequeathable assets. In the basic model of Sections 2-6, options are limited to annuities at retirement and bequeathable wealth. We find that households in the basic model often want to carry a mixture of the two assets. Section 7 gives households the option of purchasing additional (secondary) market annuities at retirement. These may carry high transaction costs. Outcomes are mixed: we find that loads at the higher end of the range reported in the literature deter households from purchasing secondary annuities; lower loads may not leaving a puzzle of why demand for secondary annuities is low in practice. In the present section, households have access to bequeathable assets, secondary annuities purchased at retirement (or, more generally, while in good health), and non-market annuities purchased at the arrival of poor health. We find that the presence of non-market annuities completely eliminates the demand for secondary annuities. Even primary annuities tend to lose at least part of their appeal.

Evidence on bequests suggests a second reason that the framework with non-market annuities may be attractive. Less than one-half of middle class families seem to leave bequests. Given thin annuitization, this seems difficult to explain. To the extent that non-market, implicit contracts within family lines are prevalent, annuitization may, in fact, not be nearly as thin as it would otherwise seem.

As stated, our model does not include intentional bequests. Nevertheless, in arguing that accidental bequests alone do not have to account for all the inheritances than we see in data, our analysis leaves room for intentional bequests as well. Our framewrok may then help to facilitate more detailed studies of private intergenerational transfers of all types in the future.

\footnotetext{
${ }^{26}$ The latter is useful because survey data may omit small inheritances.
} 


\section{Conclusion}

This paper introduces a parsimonious dynamic model of retiree behavior featuring uninsured health expenditure risks and household portfolios consisting of annuities and liquid wealth. The model incorporates sufficient detail to allow interesting calibrations, yet it remains tractable and able to provide intuitive explanations for post-retirement household behavior. The model delivers a coherent framework for interpreting three key facts on retiree financial decisions: (i) lack of decumulation of liquid assets after retirement, (ii) low demand for secondary annuities (i.e., the "annuity puzzle"), and (iii) relatively infrequent of bequests.

The model's explanation for the first fact derives from cohort composition by health status and substantial pre-annuitized wealth of households entering retirement. In particular, the distribution of households by health status becomes asymptotically stationary, making the behavior of healthy households pivotal in determining the cohort average wealth trajectories. We find that households enjoying high health status may often desire to add to their liquid assets after retirement. And, surprisingly, their willingness to do so tends to increase with their holdings of annuitized wealth.

The limited demand for market annuities can be partially explained by their inflexibility and, for secondary annuities, in particular, high transactions costs. Households choosing secondary annuities face a trade-off between inflexible income flow and a return that exceeds the interest rate on bonds. Our numerical analysis shows that when annuity loads exceed $30 \%$, household demand for secondary annuities tends to be very low.

We also put forward a less conventional explanation for the annuity puzzle. We argue that non-market annuities for the final stage of life may be important in practice (and they may be an attractive substitute for long-term care insurance). When household portfolio options include standard annuities at retirement, non-market annuities at the last stage of life, and liquid assets at all ages, we find that non-market annuities tend to dominate standard annuities (even if the latter have zero load).

What is more, the presence of non-market annuities can reconcile evidence of apparently thin annuitization with the relative paucity of bequests observed in inheritance surveys. Informal arrangements in which elderly households in poor health status exchange liquid assets, perhaps inter vivos, for in-kind assistance from grown children and other relatives provide implicit annuity protection that may have substantial value and be widespread in

practice. Future work can examine the empirical relevance of this phenomenon in more detail.

\section{Appendix}

Proof of Proposition 1. Letting $M_{S}$ be the costate variable and $\eta_{S}$ a Lagrange multiplier for the state-variable constraint $B_{S} \geq 0$, the present-value Hamiltonian is (e.g., Kamien and Schwartz [1981, p. 215])

$$
\mathcal{H} \equiv e^{-(\Lambda+\beta) s} U\left(X_{s}\right)+M_{s}\left(r B_{s}+a-X_{s}\right)+\eta_{s} B_{s} .
$$

The first-order condition for $X_{s}$ is

$$
\frac{\partial \mathcal{H}}{\partial X_{s}}=0 \Longleftrightarrow e^{-(\Lambda+\beta) s} U^{\prime}\left(X_{s}\right)=M_{s} .
$$

The costate equation is 


$$
\dot{M}_{s}=-\frac{\partial \mathcal{H}}{\partial B_{s}} \Longleftrightarrow \dot{M}_{s}=-r M_{s}-\eta_{s} .
$$

We also need

$$
\begin{gathered}
\eta_{s} \geq 0, \\
\eta_{s} B_{s}=0,
\end{gathered}
$$

as well as the budget and state-variable constraints.

Suppose $\left(B_{s}, X_{s}\right)=(0, a)$ all $s \geq T$. (34) is then satisfied when

$$
M_{s}=e^{-(\Lambda+\beta) s} U^{\prime}(a) .
$$

(35), in turn, is satisfied when

$$
\begin{gathered}
-(\Lambda+\beta) e^{-(\Lambda+\beta) s} U^{\prime}(a)=-r e^{-(\Lambda+\beta) s} U^{\prime}(a)-\eta_{s} \Leftrightarrow \\
\eta_{s}=-(r-(\Lambda+\beta)) e^{-(\Lambda+\beta) s} U^{\prime}(a) .
\end{gathered}
$$

By assumption, $-[r-(\Lambda+\beta)]>0$. So, (36) holds. (37) will then hold if and only if

$$
B_{s}=0 .
$$

Transversality condition (9) will hold any constant $B_{s}$, because $M_{s} \rightarrow 0-$ see (38).

Proof of Proposition 2. Write the Hamiltonian as in (33). Let $T<\infty$ be the time $\left(B_{T}, X_{T}\right)$ arrives at $(0, a)$ in Figure 1 . For $s \leq T$, set $M_{s}, X_{s}$, and $B_{s}$ from (6), (8), and the budget constraint $\dot{B}_{s}=r B_{s}+a-X_{s}$. And, set $\eta_{s}=0$. For $s>T$, set $M_{s}, X_{s}, B_{s}$ and $\eta_{s}$ from the proof of Proposition 1. Then the first-order condition for $X_{s}$, the costate equation, the budget equation, and the state-variable constraint hold all $s \geq 0$.

We have $\eta_{s} \geq 0$. The path of $\eta_{s}$ is piecewise continuous. By construction, $\eta_{s} B_{s}=0$. Since $B_{s}=0$ all $s \geq T$, transversality condition (9) holds. The costate variable is nonnegative. It is continuous by construction all $s$.

Proof of Proposition 3. Existence of a solution, $B_{s} \geq 0$ all $s, B_{T}=0$, and (11)-(12) follow from Propositions 1-2, Figure 1, and (8). We then have

$$
X_{0} e^{\sigma T}=a .
$$

Budgets require

$$
\left.\int_{0}^{T} e^{-r t}\left(a e^{-\sigma T} e^{\sigma t}-a\right)\right] d t=B .
$$

These determine $X_{0}$ and $T=T(a, B)$. (40) shows $T(a, 0)=0, T(a, B)$ is increasing in $B$, and $T(a, \infty)=\infty$. Differentiating $(40)$,

$$
-a \sigma e^{-\sigma T} \frac{\partial T}{\partial B} \int_{0}^{T} e^{-r t} e^{\sigma t} d t=1 .
$$

Then using (39),

$$
\frac{\partial X_{0}}{\partial B}=-\sigma a e^{-\sigma T} \frac{\partial T}{\partial B} .
$$


Combining (41)-(42), we have (13) - from which we can verify the concavity of $X_{0}(a, B)$.

Proof of Proposition 4. The dotted trajectories of Figures 3-4 satisfy necessary conditions. With strict concavity of $X_{0}(a, b)$ - see Proposition 3 - the isoclines intersect 0,1 , or 2 times. We first rule out the last. Then we show that transversality condition

$$
\lim _{s \rightarrow \infty} \mu_{s} b_{s}=0
$$

holds.

At an isocline intersection, we have

$$
\theta X_{0}(a, b)=r \cdot b+a
$$

as well as (39)-(40). (44) and (39) yield

$$
\frac{b}{a}=\frac{1}{r}\left(\theta e^{-\sigma T}-1\right) .
$$

(39)-(40) yield

$$
\begin{gathered}
\int_{0}^{T} e^{-r t}\left(e^{-\sigma T} e^{\sigma t}-1\right) d t=\frac{b}{a} \Leftrightarrow \\
e^{-\sigma T} \frac{1-e^{-(r-\sigma) T}}{r-\sigma}-\frac{1-e^{-r T}}{r}=\frac{b}{a}
\end{gathered}
$$

Combining (45)-(46),

$$
\begin{aligned}
e^{-\sigma T}\left(\frac{\theta}{r}-\frac{1}{r-\sigma}\right) & =e^{-r T}\left(\frac{1}{r}-\frac{1}{r-\sigma}\right) \Leftrightarrow \\
e^{(r-\sigma) T} & =\frac{-\sigma}{\theta(r-\sigma)-r}
\end{aligned}
$$

For $\theta(r-\sigma)>r,(47)$ has one root $T \geq 0$; hence, there is one $b^{*}$. For $\theta(r-\sigma)<r$, there are no roots $T \geq 0$; hence, there is no $b^{*}$.

Turning to the transversality condition, (43) holds in Figure 3. Consider Figure 4. We have $x_{s} \rightarrow \infty$. Then eventually $x_{s} \geq 1$. So, as $s \rightarrow \infty$,

$$
\mu_{s}=e^{-(\lambda+\beta) s} u^{\prime}\left(x_{s}\right) \leq e^{-(\lambda+\beta) s} \cdot u^{\prime}(1) .
$$

The budget constraint shows

$$
e^{-r s} b_{s}=b_{0}+\int_{0}^{s} e^{-r t}\left(a-x_{t}\right) d t \leq b_{0}+\int_{0}^{s} e^{-r t} a d t \leq b_{0}+\frac{a}{r} .
$$

So, as $s \rightarrow \infty$, we have

$$
\mu_{s} b_{s} \leq e^{-(\lambda+\beta) s} u^{\prime}(1) e^{r s}\left(b_{0}+\frac{a}{r}\right)=e^{(r-(\lambda+\beta)) s} u^{\prime}(1)\left(b_{0}+\frac{a}{r}\right) \rightarrow 0 .
$$

from assumption (a5). This establishes (43).

Proof of Proposition 5 Start with the optimization problem (10) in the low health state. Making a change of variables

$$
\bar{X}_{t}=\frac{X_{t}}{a}, \bar{B}_{t}=\frac{B_{t}}{a}
$$


yields the transformed problem

$$
\begin{gathered}
V(a, B) \equiv a^{\gamma} \max _{\bar{X}_{s}, T}\left(\int_{0}^{T} e^{-(\Lambda+\beta) s} U\left(\bar{X}_{s}\right) d s+e^{-(\Lambda+\beta) T} \frac{U(1)}{\Lambda+\beta}\right) \\
\text { subject to: } \quad \frac{d \bar{B}_{s}}{d s}=r \bar{B}_{s}+1-\bar{X}_{s}, \\
\bar{B}_{0}=\frac{B}{a} \quad \text { given. }
\end{gathered}
$$

The optimal solution to (49) depends on $(a, B)$ only through their ratio $\frac{B}{a}$ in the initial condition (50). Hence

$$
\bar{X}_{t}=\bar{X}_{t}\left(\bar{B}_{0}\right)=\bar{X}_{t}\left(\frac{B}{a}\right), \bar{B}_{t}=\bar{B}_{t}\left(\frac{B}{a}\right) .
$$

By definition of $V(\cdot, \cdot)$ in (10), the expression multiplying $a^{\gamma}$ in (49) equals $V\left(1, \frac{B}{a}\right)$ with the corresponding optimal solution $X_{t}\left(1, \frac{B}{a}\right), B_{t}\left(1, \frac{B}{a}\right)$. This establishes the following identities:

$$
V(a, B) \equiv a^{\gamma} V\left(1, \frac{B}{a}\right)
$$

and

$$
\bar{X}_{t}\left(\frac{B}{a}\right) \equiv X_{t}\left(1, \frac{B}{a}\right), \bar{B}_{t}\left(\frac{B}{a}\right) \equiv B_{t}\left(1, \frac{B}{a}\right) .
$$

Combining the last expression with (48) shows that

$$
\begin{aligned}
& X_{t}(a, B)=a \bar{X}_{t}\left(\frac{B}{a}\right) \equiv a X_{t}\left(1, \frac{B}{a}\right), \\
& B_{t}(a, B)=a \bar{B}_{t}\left(\frac{B}{a}\right) \equiv a B_{t}\left(1, \frac{B}{a}\right) .
\end{aligned}
$$

Making analogous steps with problem (15) and using (51) shows

$$
v(a, b)=a^{\gamma} v\left(1, \frac{b}{a}\right), x_{t}(a, b)=a x_{t}\left(1, \frac{b}{a}\right) .
$$

Proof of Corollary to Proposition 5 First, show that the ratio $\frac{b_{*}}{a}$ does not depend on $a$. By definition, $b_{*}$ is the intersection point of isoclines (22) and (23) described by the equation

$$
a+r b_{*}=\theta X_{0}\left(a, b_{*}\right)
$$

Dividing through by $a$ and using Proposition 5 , we get the equation for $\frac{b_{*}}{a}$ :

$$
1+r \frac{b_{*}}{a}=\theta X_{0}\left(1, \frac{b_{*}}{a}\right) .
$$

The last line shows that $\frac{b_{*}}{a}$ does not depend on $a$. Finally, from Proposition 4 and the definition of $z$, we have

$$
\dot{b}_{t} \geq 0 \Longleftrightarrow b \leq b_{*} \Longleftrightarrow z \leq z_{*} .
$$


Proof of Proposition 6 Make the following change of variables in problem (29):

$$
\alpha=\frac{a+A R}{a+b R} .
$$

Using Proposition 5, the objective function (29) can be written as

$v(a+A R, b-A)=v(\alpha(a+b R), b-A)=(a+b R)^{\gamma} v\left(\alpha, \frac{b-A}{a+b R}\right)=(a+b R)^{\gamma} v\left(\alpha, \frac{1-\alpha}{R}\right)$.

For the moment, ignore the constraint $A \geq 0$. Since $v(\cdot, \cdot)$ is concave in its arguments, $v\left(\alpha, \frac{1-\alpha}{R}\right)$ is concave and finite for all $\alpha \in[0,1]$. Therefore, it has a unique maximum

$$
\alpha_{0}=\arg \max _{\alpha \in[0,1]} v\left(\alpha, \frac{1-\alpha}{R}\right) .
$$

Now, impose the constraint $A \geq 0$, which is equivalent to $\alpha \geq \frac{a}{a+b R}$. If $\frac{a}{a+b R}<\alpha_{0}$, the constraint $A \geq 0$ is not binding and, from (52), the optimal solution is

$$
\begin{aligned}
& A=\alpha_{0} b-\left(1-\alpha_{0}\right) \frac{a}{R}, \\
& z^{\prime}=\frac{b-A}{a+A R} R_{A}=\frac{1-\alpha_{0}}{\alpha_{0}} \frac{R_{A}}{R}=\frac{1-\alpha_{0}}{\alpha_{0}} \frac{1}{1-\pi}=z_{0} .
\end{aligned}
$$

Otherwise, if $\frac{a}{a+b R} \geq \alpha_{0}$, the constraint $A \geq 0$ is binding and

$$
A=0, z^{\prime}=z .
$$

Finally, notice that

$$
\frac{a}{a+b R}<\alpha_{0} \Longleftrightarrow z>z_{0} .
$$

Hence

$$
z^{\prime}=\min \left\{z, z_{0}\right\} .
$$

Proof of Proposition 7 Suppose that $z<\bar{z}=\min \left\{z_{0}, z_{*}\right\}$. Then it must be that $z<z_{0}$, and Proposition 6 shows that $A=0$ and $z^{\prime}=z$. Since $z^{\prime}=z<z_{*}$, Proposition 5 shows that the household starting from the initial condition $z^{\prime}<z_{*}$ has $\dot{b}_{t}>0$.

Proof of Proposition 8: An Euler equation comparison of marginal utility at different ages verifies the optimality of stationary consumption in this case. Formula (31) follows.

Given (31), the marginal lifetime value of units of $B$ is

$$
\frac{r+\Lambda}{\Lambda+\beta} \cdot U^{\prime}(X)>U^{\prime}(X),
$$

where $X$ is initial consumption expenditure in poor health status and the inequality follows from our assumption that $r \geq \beta$. If the household contemplated maintaining some bequeathable assets, Section 3 and the envelope theorem show their value would be $U^{\prime}(X)$. Hence, the inequality above shows positive bequeathable net worth cannot be optimal.

Derivation of the actuarially fair rate of return on annuities Let $A$ be the market value of an annuity with income $a$. Then

$$
a=A R_{A}
$$


If $\mathbb{E}_{T}[$.$] is the expectation over \tilde{T}$, we have

$$
\begin{aligned}
A & =\mathbb{E}_{T}\left[\int_{0}^{\tilde{T}} e^{-r t} d t\right]=a \int_{0}^{\infty} \lambda e^{-\lambda T} \int_{0}^{T} e^{-r t} d t d T+ \\
& +a \int_{0}^{\infty} \lambda e^{-\lambda T} \int_{T}^{\infty} \Lambda e^{-\Lambda(S-T)} \int_{T}^{S} e^{-r s} d s d S d T .
\end{aligned}
$$

The first right-hand side term registers annuity income during the healthy phase of retirement, the second term gives income during the last phase of life. Performing the integration and combining (53)-(54), we have

$$
R_{A}=\frac{(\lambda+r)(\Lambda+r)}{\lambda+\Lambda+r}
$$

\section{References}

[1] AARP, "Valuing the Invaluable: 2011 Update," assets.aarp.org/rgcenter/ppi/ltc/fs229ltc.pdf, (2011).

[2] Ameriks, John; Caplin, Andrew; Laufer, Steven; and Stijn Van Nieuwerburgh, "The Joy of Giving or Asisted Living?" Journal of Finance Volume 66, Issue 2 (April 2011), pp 519-561.

[3] Ameriks, John, Joseph Briggs, Andrew Caplin, Matthew Shapiro and Christopher Tonetti, "Resolving the Annuity Puzzle: Estimating Life-Cycle Models without (and with) Behavioral Data", mimeo New York University.

[4] Auerbach, Alan and Kotlikoff, Laurence. Dynamic Fiscal Policy. Cambridge: Cambridge University Press, 1987.

[5] Benartzi, Shlomo, Previtero, Alessandro, and Richard H. Thaler, "Annuitization Puzzles," Journal of Economic Perspectives 25, no. 4 (Fall 2011): 143-164.

[6] Banerjee, Sudipto, "Expenditure Patterns of Older Americans, 2001-2009", Employee Benefit Research Institute Issue Brief No. 368, Feb 2012.

[7] Bernheim, B. Douglas, "Dissaving after Retirement: Testing the Pure Life Cycle Hypothesis." In Bodie, Zvi, Shoven, John B., and David A. Wise, (eds.), Issues in Pension Economics. Chicago: University of Chicago Press, 1987.

[8] Bernheim, B. Douglas, Andrei Shleifer, and Lawrence H. Summers, "The Strategic Bequest Motives," Journal of Political Economy 93, no. 6 (December 1985): 10451076.

[9] Blinder, Alan S., Gordon, Roger H., and Donald E. Wise, "Social Security, Bequests, and the Life Cycle Theory of Savings: Cross Sectional Tests," in Determinants of National Savings and Wealth, Franco Modigliani and Richard Hemming, eds., International Economic Association, 1983.

[10] Brown, Jeffrey, and Amy Finkelstein, "Supply or Demand: Why is the Market for Long-Term Care Insurance So Small?" NBER Working Paper 10782, 2004.

[11] Davidoff, Thomas, Brown, Jeffrey R., and Peter A. Diamond, "Annuities and Individual Welfare," American Economic Review 95, no. 5 (Dec. 2005): 1573-1590. 
[12] DeNardi, Mariacristina; French, Eric; and, John Bailey Jones, "Differential Mortality, Uncertain Medical Expenses, and the Saving of Elderly Singles." Federal Reserve Bank of Chicago, WP 2006-132.

[13] DeNardi, Mariacristina; French, Eric; and, John Bailey Jones, "Why Do the Elderly Save? The Role of Medical Expenses." Journal of Political Economy 118, No. 1 (February 2010): 39-75.

[14] DeNardi, Mariacristina; French, Eric; and, John Bailey Jones, "Medicaid Insurance in Old Age." Mimeo, Federal Reserve Bank of Chicago. December 2011.

[15] Diamond, Peter A., "Social Security," American Economic Review 94, no. 1 (Mar. 2004): 1-24.

[16] Dynan, Karen E. , Jonathan Skinner, and Stephen P. Zeldes, "Do the Rich Save More?" Journal of Political Economy, Vol. 112, No. 2 (April 2004), pp. 397-444

[17] Finkelstein, Amy; Luttmer, Erzo F.P.; and Matthew J. Notowidigdo, "What Good Is Wealth Without Health? The Effect of Health on the Marginal Utility of Consumption," mimeo, 2012.

[18] Friedman, B., Warshawsky, M., "The Cost of Annuities: Implications for Saving Behavior and Bequests." Quarterly Journal of Economics 105, no. 1 (1990): 135-154.

[19] French, Eric, and John Bailey Jones, "On the Distribution and Dynamics of Health Care Costs." Journal of Applied Econometrics 19, no. 6 (2004): 705-721.

[20] GAO, "Retirement Security: Challenges for Those Claiming Social Security Benefits Early and New Health Coverage Options," Report to the Chairman, Subcommittee on Primary Health and Aging, Committee on Health, Education, Labor, and Pensions, US Senate, April 2014.

[21] Horioka, Charles Y., "Are Americans More Altruistic Than the Japanese? A US-Japan Comparison of Saving and Bequest Motives," International Economic Journal 14, no. 1 (March 2000): 1-31.

[22] Hubbard, R. Glen; Skinner, Jonathan; and, Stephen P. Zeldes, "Precautionary Saving and Social Insurance." Journal of Political Economy 103, no. 2 (April 1995): 360399.

[23] Hurd, Michael D., "Savings of the Elderly and Desired Bequests," American Economic Review 77 (1987): 298-312.

[24] Hurd, Michael, D., "Mortality Risk and Bequests," Econometrica 57 (1989): 779-814.

[25] Hurd, Michael D., and Susann Rohwedder, "The Level and Risk of Out-of-Pocket Health Care Spending." MRRC Working Paper WP 2009-218, 2009.

[26] Hurd, Michael D., Paco Martorell, Adeline Delavande, Kathleen J. Mullen, Kenneth M Langa, "Monetary Costs of Dementia in the United States", The New England Journal of Medicine, v. 368, no. 14, Apr. 2013, p. 1326-1334.

[27] Kamien, Morton I., and Nancy L. Schwartz, Dynamic Optimization: The Calculus of Variations and Optimal Control in Economics and Management. New York: North Holland, Inc., 1981.

[28] Kotlikoff, Laurence J., and Lawrence H. Summers, "The Contribution of Intergenerational Transfers to Total Wealth: A Reply." In Kessler, Denis, and Andre Masson 
(eds), Modelling the Accumulation and the Distribution of Wealth. Oxford: Clarendon Press, 1988.

[29] Kotlikoff, Laurence J., and Avia Spivak, "The Family as An Incomplete Annuities Market." Journal of Political Economy 89, no. 2 (April 1981).

[30] Laibson, David, "Comment." In David A. Wise (ed.), Explorations in the Economics of Aging. Chicago: The University of Chicago Press, 2011.

[31] Laitner, John, "Bequests, Gifts, and Social Security." Review of Economic Studies 55, no. 2 (1988): 275-299.

[32] Laitner, John, and Henry Ohlsson, "Bequest Motives: A Comparison of Sweden and the United States," Journal of Public Economics 79, no. 1 (January 2001), 205-236.

[33] Laitner, John, and Dan Silverman, "Consumption, Retirement and Social Security: Evaluating the Efficiency of Reform that Encourages Longer Careers," Journal of Public Economics 96, no. 7-8 (August 2012): 615-634.

[34] Laitner, John, Dan Silverman and Dmitriy Stolyarov, "Health Status and Post Retirement Behavior", working paper, University of Michigan, 2013.

[35] Laitner, John, and Amanda Sonnega, "Intergenerational Transfers in Data from the Health and Retirement Study," Michigan Retirement Research Center working paper WP2010-238. 2010.

[36] Marshall, Samuel; McGarry, Kathleen M., and Jonathan S. Skinner, "The Risk of Outof-Pocket Health Care Expenditure at End of Life." NBER 16170. July 2010.

[37] Mirer, Thad W., "The Wealth-Age Relation among the Aged," American Economic Review 69, no. 3 (June 1979): 435-443.

[38] Mitchell, Olivia S.; James M Poterba; Mark J Warshawsky and Jeffrey R Brown, "New Evidence of the Money's Worth of Individual Annuities." American Economic Review, vol. 89, no. 5 (December 1999): 1299-1318.

[39] Modigliani, Franco, "Life Cycle, Individual Thrift, and the Wealth of Nations," American Economic Review 76, no. 3 (June 1986): 297-313.

[40] O'Brien, Ellen, "Medicaid's Coverage of Nursing Home Costs: Asset Shelter for the Wealthy or Essential Safety Net?" Long-Term Care Financing Project, Georgetown University, issue brief, May 2005.

[41] Poterba, James M., Venti, Steven F., and David A. Wise, "The Asset Cost of Poor Health." NBER 16389. September 2010.

[42] Poterba, James M., Venti, Steven F., and David A. Wise, "Family Status Transitions, Latent Health, and the Post-Retirement Evolution of Assets." In David A. Wise (ed.), Explorations in the Economics of Aging. Chicago: The University of Chicago Press, 2011.

[43] James M Poterba; Venti, Steven F; and, Wise, David A. "The Composition and DrawDown of Wealth in Retirement." Journal of Economic Perspectives. vol. 25, no. 4 (Fall 2011b), pp. 95-117.

[44] Poterba, James M., Venti, Steven F., and David A. Wise, "Were They Prepared for Retirement? Financial Status at Advanced Ages in the HRS and AHEAD Cohorts." NBER 17824. February 2012. 
[45] Prudential Pesearch Report, 2010, "Long-Term Care Cost Study", The Prudential Insurance Company of America.

[46] Reichling, Felix and Kent Smetters, "Optimal Annuitization with Stochastic Mortality Probabilities," NBER Working Paper 19211. Cambridge, MA, July 2013.

[47] Sass, Steven A., "Should You Buy an Annuity from Social Security?" Center for Retirement Research at Boston College, May 2012, Working paper 12-10.

[48] Scholz, John Karl, and Ananth Seshadri, "What Replacement Rates Should Households Use?" MRRC Working Paper WP 2009-214, 2009.

[49] Sinclair, Sven H., and Kent A. Smetters, "Health Shocks and the Demand for Annuities," Technical Paper Series Congressional Budget Office, Washington, DC, July 2004.

[50] Tobin, James, "Life Cycle Saving and Balanced Growth," in W. Fellner (ed.), Ten Economic Studies in the Tradition of Irving Fisher. New York: Wiley, 1967.

[51] Wang, Jingshu, "Motives for Intergenerational Transfers: New Test for Exchange", The American Journal of Economics and Sociology, Vol. 69, No. 2 (April, 2010), pp. 802-822.

[52] Yaari, Menahem E., "Uncertain Lifetime, Life Insurance, and the Theory of the Consumer." Review of Economic Studies 32 (April 1965): 137-150. 


\begin{tabular}{|c|c|c|c|c|c|c|}
\hline & \multicolumn{2}{|c|}{ Components of annuitized wealth, $a / R_{A}$} & \multirow{2}{*}{ Bequeathable } & \multicolumn{2}{|c|}{$z=b R_{A} / a$} \\
\cline { 2 - 3 } & SSA & DB & Medicare & wealth, $b$ & $\begin{array}{c}z, \text { Medicare } \\
\text { excluded }\end{array}$ & $\begin{array}{c}z \text {, Medicare } \\
\text { included }\end{array}$ \\
\hline Median & 230 & 0 & 180 & 100 & 0.43 & $\mathbf{0 . 2 4}$ \\
\hline 70th percentile & 299 & 73 & 180 & 272 & 0.73 & $\mathbf{0 . 4 9}$ \\
\hline Mean & 226 & 89 & 180 & 334 & 1.06 & $\mathbf{0 . 6 7}$ \\
\hline
\end{tabular}

Table 1. Components of household net worth (000s of 2008 dollars) and ratios of bequeathable to annuitized wealth. Source: Poterba et al. [2011], Table 1, 2 and p. 99.

\begin{tabular}{|c|c|c|c|c|c|c|c|c|c|}
\hline \multirow{2}{*}{$\gamma$} & \multicolumn{3}{|c|}{$\omega^{\frac{\gamma}{1-\gamma}}=3.64$} & \multicolumn{3}{c|}{$\omega^{\frac{\gamma}{1-\gamma}}=3.00$} & \multicolumn{3}{c|}{$\omega^{\frac{\gamma}{1-\gamma}}=4.00$} \\
\cline { 2 - 10 } & $r=0.02$ & $r=0.03$ & $r=0.04$ & $r=0.02$ & $r=0.03$ & $r=0.04$ & $r=0.02$ & $r=0.03$ & $r=0.04$ \\
\hline-0.5 & 0.64 & 1.07 & 2.23 & 0.40 & 0.64 & 1.14 & 0.8 & 1.39 & 3.33 \\
\hline-1.0 & 0.93 & 1.66 & 4.58 & 0.57 & 0.91 & 1.75 & 1.19 & 2.3 & 10.8 \\
\hline-1.5 & 1.30 & 2.61 & 29.18 & 0.76 & 1.27 & 2.85 & 1.69 & 4.02 & $\infty$ \\
\hline-2.0 & 1.75 & 4.41 & $\infty$ & 0.98 & 1.77 & 5.68 & 2.35 & 9.03 & $\infty$ \\
\hline-2.5 & 2.34 & 9.67 & $\infty$ & 1.24 & 2.50 & $\infty$ & 3.29 & $\infty$ & $\infty$ \\
\hline-3.0 & 3.14 & $\infty$ & $\infty$ & 1.55 & 3.72 & $\infty$ & 4.74 & $\infty$ & $\infty$ \\
\hline-5.0 & 22.85 & $\infty$ & $\infty$ & 3.79 & $\infty$ & $\infty$ & $\infty$ & $\infty$ & $\infty$ \\
\hline
\end{tabular}

Table 2. Long-run ratio of bequeathable wealth to annuitized wealth $z_{*}$. Other parameters: $\beta=0.02, \lambda=\frac{1}{12}, \Lambda=\frac{1}{3}$.

\begin{tabular}{|c|c|c|c|c|c|}
\hline \multirow{3}{*}{$\begin{array}{l}\text { Model real } \\
\text { interest } \\
\text { rate, } \\
r\end{array}$} & \multirow{3}{*}{$\begin{array}{l}\text { Actuarially } \\
\quad \text { fair } \\
\text { annuity } \\
\text { return, } R_{A}\end{array}$} & \multicolumn{4}{|c|}{$\begin{array}{c}\text { Rate of return differentials } \\
\Delta r_{T}-\text { individual rate of return on annuities less Treasury bond yield } \\
\Delta r_{C}-\text { individual rate of return on annuities less corporate bond yield }\end{array}$} \\
\hline & & \multicolumn{2}{|c|}{$\begin{array}{c}\text { Friedman and Warshawsky } \\
{[1990, \text { Table III }]}\end{array}$} & \multicolumn{2}{|c|}{$\begin{array}{c}\text { Mitchell et al. } \\
{[1999, \text { Table } 4]}\end{array}$} \\
\hline & & $\Delta r_{T}=-0.0421$ & $\Delta r_{C}=-0.0613$ & $\Delta r_{T}=-0.0221$ & $\Delta r_{C}=-0.0369$ \\
\hline 0.02 & 0.0836 & 0.42 & 0.61 & 0.22 & 0.37 \\
\hline 0.03 & 0.0922 & 0.39 & 0.56 & 0.21 & 0.34 \\
\hline 0.04 & 0.1008 & 0.36 & 0.51 & 0.19 & 0.31 \\
\hline
\end{tabular}

Table 3. Annuity load factor $\pi$ calculated from the empirical rate of return differentials. 


\begin{tabular}{|c|c|c|c|c|c|c|c|}
\hline & \multicolumn{3}{|c|}{$r=0.02$} & \multicolumn{2}{c|}{$r=0.03$} & \multicolumn{2}{c|}{$r=0.04$} \\
\hline$\gamma$ & $\pi=0.2$ & $\pi=0.3$ & $\pi=0.4$ & $\pi=0.3$ & $\pi=0.4$ & $\pi=0.3$ & $\pi=0.4$ \\
\hline-0.5 & 0.31 & 0.64 & 0.64 & $\mathbf{0 . 7 7}$ & $\mathbf{1 . 0 7}$ & $\mathbf{0 . 7 8}$ & $\mathbf{2 . 2 3}$ \\
\hline-1.0 & 0.27 & 0.64 & $\mathbf{0 . 9 3}$ & 0.65 & $\mathbf{1 . 6 6}$ & 0.61 & $\mathbf{2 . 3 3}$ \\
\hline-1.5 & 0.24 & 0.56 & $\mathbf{1 . 3 0}$ & 0.54 & $\mathbf{1 . 5 3}$ & $\mathbf{2 9 . 1 8}$ & $\mathbf{2 9 . 1 8}$ \\
\hline-2.0 & 0.25 & 0.49 & $\mathbf{1 . 1 3}$ & 0.54 & $\mathbf{1 . 3 3}$ & na & na \\
\hline-2.5 & 0.24 & 0.48 & $\mathbf{0 . 9 9}$ & 0.50 & $\mathbf{1 . 1 8}$ & na & na \\
\hline-3.0 & 0.23 & 0.45 & $\mathbf{0 . 9 2}$ & na & na & na & na \\
\hline-5.0 & $\leq 0.20$ & 0.35 & 0.68 & na & na & na & na \\
\hline
\end{tabular}

Table 4. Threshold ratio of bequeathable wealth to annuitized wealth, $\bar{z}$, from Proposition 7. Entries where Figure 4 phase diagram applies are labelled with "na".

Other parameters: $\omega^{\frac{\gamma}{1-\gamma}}=3.64, \beta=0.02, \lambda=\frac{1}{12}, \Lambda=\frac{1}{3}$.

\begin{tabular}{|c|c|c|c|c|c|c|c|c|c|}
\hline \multirow{2}{*}{$\gamma$} & \multicolumn{3}{|c|}{$\omega^{\frac{\gamma}{1-\gamma}}=3.64$} & \multicolumn{3}{c|}{$\omega^{\frac{\gamma}{1-\gamma}}=3.00$} & \multicolumn{3}{c|}{$\omega^{\frac{\gamma}{1-\gamma}}=4.00$} \\
\cline { 2 - 10 } & $r=0.02$ & $r=0.03$ & $r=0.04$ & $r=0.02$ & $r=0.03$ & $r=0.04$ & $r=0.02$ & $r=0.03$ & $r=0.04$ \\
\hline-0.5 & 0.79 & 1.16 & 1.86 & 0.57 & 0.81 & 1.23 & 0.92 & 1.38 & 2.31 \\
\hline-1.0 & 0.79 & 1.10 & 1.65 & 0.57 & 0.78 & 1.10 & 0.92 & 1.31 & 2.03 \\
\hline-1.5 & 0.79 & 1.07 & 1.53 & 0.57 & 0.76 & 1.03 & 0.92 & 1.27 & 1.88 \\
\hline-2.0 & 0.79 & 1.05 & 1.46 & 0.57 & 0.74 & 0.99 & 0.92 & 1.25 & 1.79 \\
\hline-2.5 & 0.79 & 1.04 & 1.42 & 0.57 & 0.73 & 0.96 & 0.92 & 1.23 & 1.73 \\
\hline-3.0 & 0.79 & 1.03 & 1.38 & 0.57 & 0.72 & 0.94 & 0.92 & 1.22 & 1.69 \\
\hline-5.0 & 0.79 & 1.00 & 1.31 & 0.57 & 0.71 & 0.89 & 0.92 & 1.19 & 1.59 \\
\hline
\end{tabular}

Table 5. Threshold ratio of bequeathable wealth to annuitized wealth, $\bar{z}$, from Proposition 7 corresponding to value function $\bar{v}$.

Other parameters: $\beta=0.02, \lambda=\frac{1}{12}, \Lambda=\frac{1}{3}$. 


\begin{tabular}{|c|c|c|c|c|c|c|c|c|c|}
\hline \multirow{2}{*}{$\gamma$} & \multicolumn{3}{|c|}{ Initial condition $z=0.3$} & \multicolumn{3}{c|}{ Initial condition $z=0.4$} & \multicolumn{3}{c|}{ Initial condition $z=0.5$} \\
\cline { 2 - 10 } & $r=0.02$ & $r=0.03$ & $r=0.04$ & $r=0.02$ & $r=0.03$ & $r=0.04$ & $r=0.02$ & $r=0.03$ & $r=0.04$ \\
\hline-0.5 & $0.83 / 0.58$ & $0.84 / 0.61$ & $0.86 / 0.63$ & $0.85 / 0.63$ & $0.86 / 0.66$ & $0.87 / 0.68$ & $0.87 / 0.67$ & $0.88 / 0.69$ & $0.89 / 0.71$ \\
\hline-1.0 & $0.89 / 0.68$ & $0.90 / 0.70$ & $0.91 / 0.72$ & $0.91 / 0.73$ & $0.91 / 0.75$ & $0.92 / 0.76$ & $0.92 / 0.77$ & $0.93 / 0.78$ & $0.93 / 0.79$ \\
\hline-1.5 & $0.93 / 0.75$ & $0.93 / 0.77$ & $0.94 / 0.78$ & $0.94 / 0.80$ & $0.94 / 0.81$ & $0.95 / 0.82$ & $0.95 / 0.83$ & $0.95 / 0.84$ & $0.96 / 0.85$ \\
\hline-2.0 & $0.95 / 0.80$ & $0.95 / 0.81$ & na & $0.96 / 0.84$ & $0.96 / 0.85$ & na & $0.97 / 0.87$ & $0.97 / 0.88$ & na \\
\hline-2.5 & $0.96 / 0.84$ & $0.97 / 0.85$ & na & $0.97 / 0.88$ & $0.97 / 0.88$ & na & $0.98 / 0.90$ & $0.98 / 0.91$ & na \\
\hline-3.0 & $0.97 / 0.87$ & na & na & $0.98 / 0.90$ & na & na & $0.98 / 0.92$ & na & na \\
\hline-5.0 & $0.99 / 0.93$ & na & na & $0.99 / 0.95$ & na & na & $1.00 / 0.97$ & na & na \\
\hline
\end{tabular}

Table 6. Basic model: fraction of households dying with a bequest $>0 />a$. Entries where Figure 4 phase diagram applies are labelled with "na".

Other parameters: $\omega^{\frac{\gamma}{1-\gamma}}=3.64, \beta=0.02, \lambda=\frac{1}{12}, \Lambda=\frac{1}{3}$. 